\title{
Biomass Thermochemical Conversion Program 1983 Annual Report
}

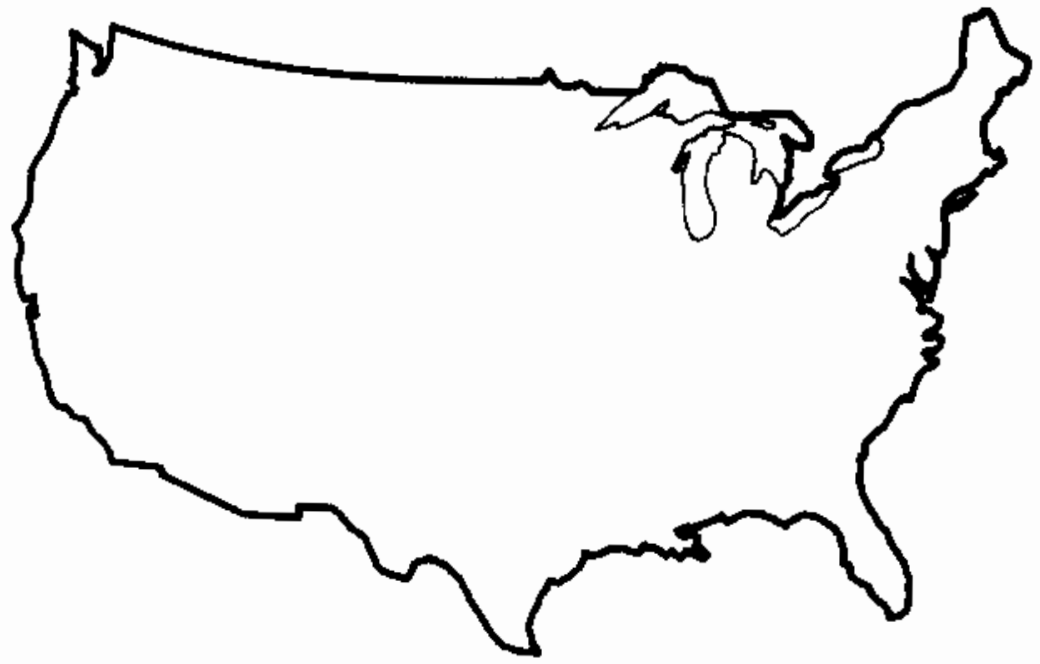

August 1984

G. F. Schiefelbein

D. ). Stevens

M. A. Gerber

Biomass Program Office

Pacific Northwest Laboratory

Operated for the U.S. Department of Energy

by Battelle Memorial Institute 


\title{
DISCLAIMER
}

This report was prepared as an account of work sponsored by an agency of the United States Government. Neither the United States Government nor any agency thereof, nor any of their employees, makes any warranty, express or implied, or assumes any legal liability or responsibility for the accuracy, completeness, or usefulness of any information, apparatus, product, or process disclosed, or represents that its use would not infringe privately owned rights. Reference herein to any specific commercial product, process, or service by trade name, trademark, manufacturer, or otherwise, does not necessarily constitute or imply its endorsement. recommendation, or favoring by the United States Government or any agency thereof. The views and opinions of authors expressed herein do not necessarily state or reflect those of the United Stares Government or any agency thereof.

\author{
PACIFIC NORTHWEST LABORATORY \\ operated by \\ BATTELLE \\ for the \\ UNITED STATES DEPARTMENT OF ENERGY \\ under Contract DE-AC06-76RLO 1830
}

\begin{tabular}{|c|c|}
\hline \multicolumn{2}{|c|}{ Printed in the United 5tates of America } \\
\hline \multicolumn{2}{|c|}{$\begin{array}{c}\text { Available from } \\
\text { National Technical Information Service }\end{array}$} \\
\hline \multicolumn{2}{|c|}{$\begin{array}{l}\text { National Technical Information Service } \\
\text { Lnited States Depanment of Commerce }\end{array}$} \\
\hline \multicolumn{2}{|c|}{5285 Port Royal Road } \\
\hline \multicolumn{2}{|c|}{ Springfield, Virginia 22161} \\
\hline \\
\hline \multicolumn{2}{|c|}{ Microfiche A01 } \\
\hline \multicolumn{2}{|c|}{ Printed Copy } \\
\hline & Price \\
\hline Pages & Codes \\
\hline $001-025$ & $\mathrm{~A} 02$ \\
\hline $026-050$ & $\mathrm{~A} 03$ \\
\hline $057-075$ & AOA \\
\hline $076-100$ & A05 \\
\hline $101-125$ & A06 \\
\hline $126-150$ & $\mathrm{~A} 07$ \\
\hline $151-175$ & $A 08$ \\
\hline $176-200$ & $A 09$ \\
\hline $201-225$ & A070 \\
\hline $226-250$ & A011 \\
\hline $251 \cdot 275$ & A012 \\
\hline $276-300$ & A013 \\
\hline
\end{tabular}



G. F. Schiefelbein
D. J. Stevens
M. A. Gerber

August 1984

Prepared for the U.S. Department of Energy under Contract DE-ACD6-76RLO 1830

Pacific Northwest Laboratory Richland, Washington 99352 


\section{EXECUTIVE SUMMARY}

Biomass represents an important but underutilized energy resource in the United States. The Congressional Office of Technology Assessment has estimated that, with proper resource management and the development of efficient conversion processes, the potential contribution of biomass to U.S. energy demand could range as high as 17 quadrillion Btu per year--almost $20 \%$ of current U.S. energy consumption. Similarly, the Energy Research Advisory Board (ERAB) has estimated a potential of approximately 10 quadrillion Btu per year.

Wood and crop residues constitute a vast majority of the biomass feedstocks available for conversion, and thermochemical processes are well suited for conversion of these materials. The U.S. Department of Energy (DOE) is sponsoring research on this conversion technology for renewable energy through its Biomass Thermochemical Conversion Program.

The program is part of DOE's Biomass Energy Technology Division, Office of Renewable Energy. Pacific Northwest Laboratory has been designated the Field Management Office for the Biomass Thermochemical Conversion Program with responsibility for overall management of the program. This report briefly describes the Thermochemical Conversion Program structure and summarizes the activities and major accomplishments during fiscal year 1983.

\section{PROGRAM OBJECTIVE, GOAL, ANO STRATEGY}

The objective of the Biomass Thermochemical Conversion Program is to generate scientific data and conversion process information that will lead to establishment of cost-effective processes for converting biomass resources into clean fuels. The goal of the program is to develop the data base for biomass thermal conversion by investigating the fundamental aspects of conversion technologies and by exploring those parameters that are critical to the conversion processes.

Thermochemical conversion processes employ elevated temperatures to convert biomass materials into energy. Process examples include:

- gasification to produce fuel gas or synthesis gases for the production of methanol and hyorocarbon fuels 
- direct 1 iquefaction and pyrolysis to produce heavy oils or a mixture of oils, fuel gases, and char

- combustion to produce heat, steam, electricity, and direct mechanical power.

Compared to other solid fuels such as coal, biomass feedstocks have unique properties that offer great potential advantages for thermochemical conversion processes. Biomass is highly reactive; thus, feedstocks can be decomposed and converted at much lower temperatures than coals, making these processes more efficient and competitive at smaller scale. Biomass feedstocks also have much lower ash and sulfur content than coals. The lower sulfur content greatiy reduces gas cleanup costs and allows biomass to be reacted directly with catalysts without catalyst poisoning problems. The research activities sponsored by the Biomass Thermochemical Conversion Program are directed toward exploiting these properties of biomass.

PROGRAM RESEARCH AREAS

The research activities sponsored by the Thermochemical Conversion Program can be divided into four areas:

1. Gasification Technology

2. Liquid Fuels Technology

3. Direct Combustion Technology

4. Frogram Support Activities.

The following sections briefly describe program activities and major accomp 1 ishments in each of these areas for fiscal year 1983. Gasification Technology

Gasification of biomass can be achieved by reacting biomass with steam, at moderately high temperatures, to produce a combustible gas mixture containing large quantities of hydrogen and carbon monoxide. Heat is provided to the gasification reactor either by combusting a portion of the biomass with air or oxygen, or by indirectly heating the reactor. When air is used to heat the gasifier, the nitrogen in the air significantly dilutes the product gas, and a low-Btu gas with a heating value of 90 to $200 \mathrm{Btu} / \mathrm{scf}$ is produced. Low-Btu 
fuel gas is limited by the restrictions that the gas must be used at or near the site of production in a close-coupled process. The high nitrogen content of low-Btu gas precludes its use for synthesis of liquid fuels.

If heat is supplied to the gasifier using oxygen or indirect methads instead of air, nitrogen is eliminated, and a medium-Btu gas product with a heating value ranging from 300 to $600 \mathrm{Btu} / \mathrm{scf}$ can be produced. Medium-Btu gas is suitable for substitution for fuel oil and natural gas in most applications and for the synthesis of riquid fueis.

The gasification research activities sponsored by the Biomass Thermochemjcal Conversion Program are directed toward exploiting the unique properties of biomass. Primary emphasis has been on production of a medium-Btu gas for either fuel or synthesis gas uses. In addition, research has also been conducted to improve the performance and reliability of low-Btu gasifiers. Specific research projects include:

- production of a medium-Btu gas without using purified oxygen at BattelleColumbus Laboratories

- high pressure (up to 500 psia) steam-oxygen gasification of biomass in a fluidized bed reactor at the Institute of Gas Technology

- producing synthesis gas via catalytic gasification at Pacific Northwest Laboratory

- indirect reactor heating methods at the University of Missouri-Rolla and Texas Tech University

- improving the reliability, performance, and acceptability of small air-blown gasifiers at University of Florida-Gainesville, Rocky Creek Farm Gasogens, and Cal Recovery Systems.

\section{Liquid Fuels Technology}

The Biomass Thermochemical Conversion Program is sponsoring research on the production of hydrocarbon-compatible liquid fuels from biomass. Two approaches--fast pyrolysis and direct liquefaction--are currently being investigated.

Pyrolysis refers to the thermal decomposition of biomass in an oxygen-free 
environment. Conventional pyrolysis produces products consisting of about one-third each gases, pyrolysis oil, and char. Researchers have discovered that the yields of higher-valued light liquid hydrocarbons and gases can be increased to greater than $95 \%$ if biomass is heated very rapidly. These high-valued products contain up to $20 \%$ ethylene and BTX (benzene, toluene, and xylene), which are useful as fuels and octane enhancers.

Direct liquefaction refers to a specific process in which biomass is heated at moderate temperatures $\left(350^{\circ} \mathrm{C}\right)$ and high pressures $(3000 \mathrm{psi})$ with a catalyst in a reducing atmosphere of carbon monoxide and hydrogen. The goal of this research is to produce liquid products that can be used as substitute heavy fuel oils or, after upgrading, as distillate fractions, diesel fuels, octane enhancers, and in other related applications.

During 1983, the Thermochemical Conversion Program sponsored research in both liquid fuel technology areas. Research has focused on developing a better understanding of the basic reaction mechanisms governing these processes and on improving the competitiveness of these technology concepts. Specific projects include:

- determination of individual sequential pyrolysis mechanisms at the Solar Energy Research Institute (SERI)

- research at the Solar Energy Research Institute on a unique entrained, ablative fast pyrolysis reactor for supplying the heat fluxes reauired for fast pyrolysis

- work at Brookhaven Nationai Laboratory on rapid pyrolysis of biomass in an atmosphere of methane ta increase the yields of olefin and BTX products

- research at the Georgia Institute of Technology on an entrained rapid pyrolysis reactor to produce higher yields of pyrolysis oil

- research on an advanced concept to liquefy very concentrated biomass slurries in an integrated extruder/static mixer reactor at the University of Arizona

- research at Pacific Northwest Laboratory on the characterization and upgrading of direct liquefaction oils including research to lcwer oxygen content and viscosity of the product. 


\section{Direct Combustion Technology}

Direct combustion of biomass feedstocks, particularly wood, is already widely practiced by the private sector. Direct combustion projects funded by the Biomass Thermochemical Conversion Program have focused on unique, innovative combustion systems. These include:

- research on a directly fired wood combustor/gas turbine system at Aerospace Research Corporation

- adaptation of Stirling engine external combustion systems to biomass fuels at United Stirling, Incorporated

- theoretical modeling and experimental verification of biomass combustion behavior at Jet Propulsion Laboratory to increase biomass combustion efficiency and examine the effects of additives on combustion rates. Program Support Activities

During 1983, the Thermochemical Conversion Program sponsored additional research activities with the goal of supporting major program elements. These activities included:

- completion of a study by Pyros, Incorporated, on the wood supply infrastructure in the eastern U.S. for supplying wood to intermediate size (500 to 2000 tons/day) biomass conversion facilities

- continuing technoeconomic analysis by Science Applications, Incorporated, of advanced biomass thermochemical conversion processes for producing liquid fuels, with particular emphasis on advanced pyrolysis concepts

- research at Georgia Tech on methods to reduce aqueous effluents in biomass gasirication systems

- research at Dynecology, Incorporated, to determine the feasibility of using biomass/coal/municipal solid waste (MSW) briquets in coal gasification systems. 
OUTSTANDING ACCOMPLISHMENTS IN 1983

The Biomass Thermochemical Conversion Program made major progress in 1983 toward verifying the technical feasibility of several advanced technology concepts. These state-of-the-art research concepts offer the potential for significant advancement of biomass conversion technology. In addition, progress was made at the fundamental level in understanding the reaction behavior involved in upgrading biomass liquefaction products. Outstanding accomplishments of the Biomass Thermochemical Conversion Program during fiscal year 1983 include:

- Successfui Extended Operation of Combustor/Gas Turbine System. Aerospace Research Corporation successfully showed that combustion gases from a pressurized wood combustor can be used to directiy power a gas turbine for extended time periods. A $375-\mathrm{kW}$ gas turbine was operated for approximately 500 hours without evidence of corrosion or erosion of turbine components. The experimental testing verified eariier sampling showing that particulate loading in the gas stream to the turbine was low and would meet operational requirements. The sampling indicated that 80 to $90 \%$ of the particulate was less than 0.5 micron. The results of this research have been used to design a larger $3000-\mathrm{kW}$ system, which is currently nearing completion. Operation of the $3000-\mathrm{kW}$ system is expected in 1984. This research is the first to successfully use biamass combustion gases to directly power a gas turbine.

- Successful Production of Medium-Btu Fuel Gas Using an Indirectly Heated, Dual Bed Gasifier. Battelle-Columbus Laboratories successfully produced a medium-Btu fuel gas in an indirectly heated dual bed gasifier. The entrained bed gasifier uses sand that has been heated in a separate combustor to provide heat for the biomass conversion reactions. The indirect heating eliminates the need for expensive oxygen purification equipment. Throughput in the reactor, based upon cross-sectional area, is about three times greater than in conventional fluidized beds, and about ten times greater than in fixed beds. During 1983, the gasifier diameter was increased from 6 inches to 10 inches ID. The modified 
reactor operated successfully, obtaining even higher conversion efficiencies than previously obtained in the small unit. Feeding rates up to the gasifier design capacity of about 1100 pounds per hour were achieved.

- Successful Oxygen-Blown Biomass Gasification in a Pressurized Fluidized Bed Reactor. The Institute of Gas Technology verified that biomass could be gasified to a medium-Btu gas in an oxygen-blown, pressurized, fluidized bed gasifier. Initial tests showed that about 0.4 pound of oxygen per pound of dry wood were consumed during gasification. The gas produced during initial operation also had a $\mathrm{H}_{2} / \mathrm{CO}$ ratio of about 2 , which is ideal for synthesis.

- Successful Operation of Indirectly Heated Gasifier Using a Fire-Tube Heat Exchanger Concept. Research at the University of Missouri-Rolla successfully showed that bionass could be gasified in a fluidized bed reactor using a fire-tube heat exchanger. In this gasifier concept, heat for gasification reactions is provided by hot combustion gases passing through a fire-tube heat exchanger inside the gasifier. The concept eliminates the need for oxygen and would be particularly useful for catalytic gasification systems where oxygen addition would destroy the catalysts. The concept was successfully tested during 1983 in a 20 -inch gasifier. Heat exchange rates were approximately as predicted, and the mixirg in the fluidizing section appeared to be excellent. Wood feed rates of up to 400 pounds per hour (10\% moisture) were achieved. These results are the first verification of the technical feasibility of this type of concept.

- Produced High Yjelds of Liquid 0il Products Using an Entrained Pyrolysis Reactor. Georgia Tech successfully operated a newly constructed pyrolysis reactor for generating liquid products. The reactor is an entrained flow pyrolysis unit in which both feedstock heat-up rates and product quench rates are rapid. During 1983, yields of pyrolytic oils exceeding $40 \%$ by weight (moisture-free basis) were obtained. This represents nearly a twofoid increase in yield over conventional pyrolysis processes, which produce only 20 to $25 \%$ moisture-free liquid products. 
Further research is expected to result in even higher liquid yields as process conditions are optimized.

- Showed That Biomass Derived Crude 0ils Could Successfully be Hydrotreated to Obtain Synthetic Gasoline. Pacific Northwest Laboratory successfully conducted upgrading studies of biomass direct liquefaction oils. The purpose of the work is to produce a high octane gasoline blending stock that retains the aromatic components of the biomass feedstock. Unlike conventional exhaustive hydrotreating, which would reduce the biomass oils to low octane, straight-chain hydrocarbons, this approach uses less hydrogen and retains higher-valued aromatic components. Biocrude oils previously produced at the DOE biomass liquefaction facility in Albany, Oregon, were treated using a sulfided colbalt-molybdenum catalyst. Distillate fractions were successfully converted to high octane gasoline components. Research on upgrading the biomass whole oils is continuing. 


\section{CONTENTS}

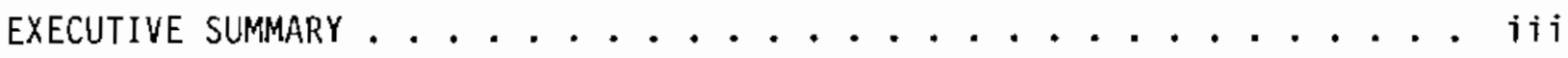
INTRODUCTION . . . . . . . . . . . . . . . . . . . . . . . . 1

PROGRAM DESCRIPTION . . . . . . . . . . . . . . . . . . . 3

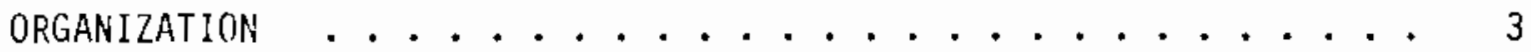

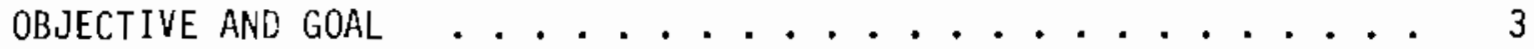

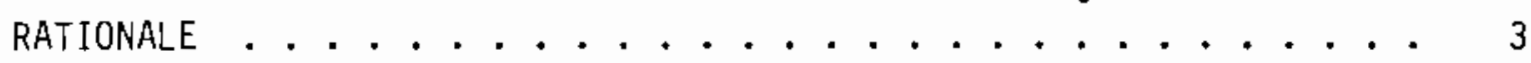

APPROACH ................................ 8

PROGRAM RESEARCH AREAS . . . . . . . . . . . . . . . . 12

GASIFICATION TECHNOLOGY . . . . . . . . . . . . . 12

Medium-Btu Gasification Research ............ 17

Low-Btu Gasification Research . . . . . . . . . . . 24

LIQUID FUELS TECHNOLOGY . . . . . . . . . . . . . . . . . 25

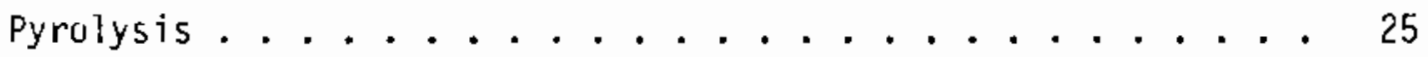

Direct Liquefaction .................... 31

DIRECT COMBUSTIOH TECHNOLOGY . . . . . . . . . . . . . . 34

PROGRAM SUPPORT ACTIVITIES ................. 40

Additional Information ................ 43

$\begin{aligned} \text { APPENDIX - } & \text { BIOMASS THERMOCHEMICAL CONVERSION } \\ & \text { PROGRAM PUBLICATIONS FOR } 1983 \ldots \ldots \ldots \ldots . \ldots . \ldots . \ldots\end{aligned}$ 
, 


\section{FIGURES}

1 Relationship of Biomass Thermochernical Conversion Program to Biomass Energy Technology Division Organization ...... 4

2 Biomass Thermochericai Conversion Processes Produce Versatile Fuets ................... 6

3 Pyrolytic Weight Loss Comparison: Wood Versus Coal . . . . . 7

4 Char Reactivity Comparison: Biomass Feedstocks Versus Peat and Coal ................... 8

5 Conceptual Approach to Biomass Thermochemical Conversion Research .................... 10

6 Government and Private Industry Interaction in Biomass Thermochemical Conversion Research ........... 11

7 Thermochemical Gasification of Biomass .......... 13

8 Gasification Research Projects ............. 16

9 Battelle-Columbus Dual Bed, Entrained Gasifier Process . . . 17

10 Battelle-Columbus Dual Bed, Entrained Gasifier ........ 18

11 Product Gas Heating Vaiue Versus Feedstock Moisture . . . . . . 19

12 Institute of Gas Technology Fluidized Bed Gasifier ...... 20

13 Metal Fire-Tube Heat Exchangers Inside Fluidized Bed

14 Pacific Northwest Laboratory Catalytic, Fluidized Bed Gasifier . 23

15 Liquid Fuels Research Projects ............ 26

16 Competing Reactions During Biomass Pyrolysis ........ 2B

17 Rapid Pyrolysis Research Reactor at Solar Energy Research

18 Comparison of Biomass Pyrolysis Products in Inert and Metharie Atmospheres ............... 3D

19 Entrained-Fiow Pyrolysis Process at Georgia Tech ....... 31

20 Georgia Tech Pyrolysis Unit . . . . . . . . . . . 32 


\section{FIGURES cont}

21 University of Arizona Extruder/Static Mixer Direct Liquefaction Reactor ............. 34

22 Direct Combustion Research Projects ........... 36

23 Combustor/Gas Turbine System at Aerospace Research Corporation - 37

24 Two-stage Combustor and Cyclones for 3-MW Combustor/Gas Turbine System at Aerospace Research Corporation . . . . . . 38

25 3-MW Gas Turbine and Generator Set at Aerospace Research Corporation . . . . . . . . . . . . . 39

26 Program Support Research Projects . . . . . . . . . . . 41

TABLE

1 Biomass Liquefaction Product Comparative Analyticai Data . . . . 35 


\section{BIOMASS THERMOCHEMICAL. CONVERSION PROGRAM \\ 1983 ANNUAL REPORT}

\section{INTRODUCTION}

Biomass represents an important but underutilized energy resource in the United States. Wood and forest product residues, grasses, agricultural crops and their residues, animal wastes, and other biomass resources currentiy supply nearly $3 \%$ of total U.S. energy consumption. As an abundant, renewable, domestic energy resource, biomass can help the United States reduce its dependence on imported oil and natural gas.

The Office of Technology Assessment has estimated that, with proper resource management and the development of efficient conversion processes, the potential contribution of biomass to the U.S. energy denand could range as high as 17 quadrillion Btu per year (a). This amounts to almost $20 \%$ of current U.S. energy corisumption. Similarly, the Energy Research Advisory Board (ERAB) has estimated that bionass could potentially supply the nation with about 10 quadrillion Btu by the year $2000^{(b)}$. Thermochemical conversion processes are expected to contribute significantly to this total.

The U.S. Department of Energy (DOE) is actively encouraging increased utilization of bionass resources through research projects sponsored by its Biomass Energy Technology Livision, Office of Renewable Energy. Pacific Northwest Laboratory (PNL) ${ }^{(C)}$ has been designated the Field Vanagement office for the Biollass Thermochemical Conversion Program. As such, PNL has responsibility for overali management of the program.

This report first describes the Biomass Thermochemical Conversion Program: its organizätion, underlying objective, and goal, rationàle, and

(a) Office of Technology Assessment, 1980. Energy from Biological Processes, Volume I - Biomass Resource Base. U.S. Goverment Printing Office, Washington, D.C.

(b) Solar Energy Research and Developmerit: Federal and Private Sector Roles, Draft Report to the Solar R\&D Panel of the Energy Research Advisory Board, September 2, 198z.

(c) Operated for the U.S. Department of Energy by Battelle Memorial Institute. 
approach. Then, the program subcontracted research activities during fisca? year 1983 are documented. Program publications issued in FY83 are listed in the Appendix. 


\section{PROGRAM DESCRIPTION}

The Biomass Thermochemical Conversion Program began in 1977 as one aspect of DOE's overall effort to develop renewable energy resources in the U.S. The recognized potential of biomass as a significant contributor to meet the nation's energy demand suggested the need for research into more efficient processes for converting the resource into usable energy. This section describes the Thermochemical Conversion Program's role in meeting that need.

\section{ORGANIZATION}

The relationship of the Biomass Thermochemical Conversion Program to other programs within DOE's Biomass Energy Technology Division is shown in Figure 1.

\section{OBJECTIVE AND GOAL}

The objective of the Biomass Thermochemical Conversion Program is to generate scientific data and biomass conversion process information that will lead to establishment of cost-effective processes for conversion of biomass resources into clean fuels. Areas of research included in the program are gasification, liquid fuels production, and combustion of biomass. The goal of the program is to improve the data base for biomass conversion by investigating those parameters that are critical to thermal conversion processes.

\section{RATIONALE}

Thermochemical conversion processes employ elevated temperatures to convert biomass materials to more useful energy forms. Process examples include:

- combustion to produce heat, steam, electricity, direct mechanical power, and combinations of these

- gasification to produce low- or intemediate-energy fuel gâs

- gasification to produce synthesis gas for the production of alcohol fuels, hydrocarbon liquids, or synthetic natural gas (SNG) via catalytic 


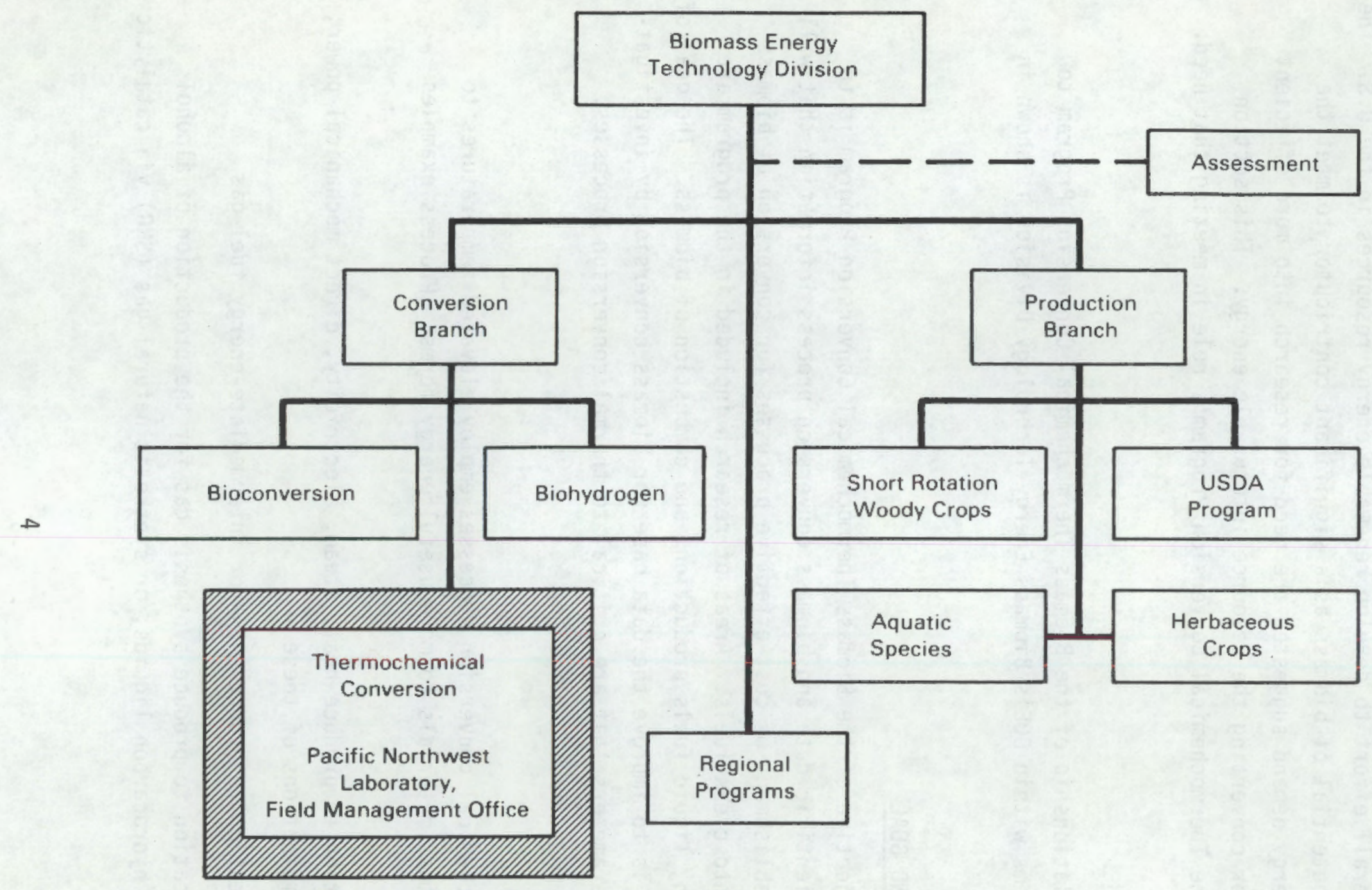

FIGURE 1. Relationship of Biomass Thermochemical Conversion Program to Biomass Energy Technology Division Organization 
processes

- direct liquefaction to produce heavy oils or, with upgrading, lighter boiling liquid products

- pyrolysis to produce a mixture of pyrolysis oils, fuel gases, and char. Wood and crop residues comprise $96 \%$ of biomass feedstocks available for conversion to liquid and gaseous fuels. Thermochemical processes are well suited for conversion of these materials. These processes can convert 85 to 95\% of the organic material in such feedstocks with high efficiency and relatively little sensitivity to variations in the feed material. As illustrated in Figure 2, thermochemical conversion processes can provide a wide spectrum of versatile products congruent with U.S. energy use patterns.

Compared to other solid fuels such as coal, biomass feedstocks have unique properties that offer great potential advantages for thermochemical conversion processes. These properties include:

- high volatility - Biomass feedstocks contain a high proportion of volatile nlaterial, 70 to $90 \%$ for wood compared to 30 to $45 \%$ for typical coals. This means that a large fraction of most biomass feedstocks can be pyrolyzed (devolatilized) rapidly at relatively low temperatures. Figure 3 presents a comparison of wood and one typical coal in terms of weight loss due to devolatilization at various temperatures.

- high char reactivity - Biomass chars gasify rapidly in the presence of steam at relatively low temperatures. This property is illustrated in Figure 4 , which compares the char reactivity of some biomass feedstocks with peat and coal at $800^{\circ} \mathrm{C}$ and 300 psi in the presence of steam.

- low sulfur content - Typical wood feedstocks contain less than $0.2 \%$ sulfur, which greatly reduces gas cleanup costs and allows bionass to be reacted in the presence of catalysts without sulfur poisoning problems.

- low ash content - Wood and most other bjomass feedstocks contain less than 3.0\% ash. Ash removal systems are simplified and ash disposal costs are reduced. 


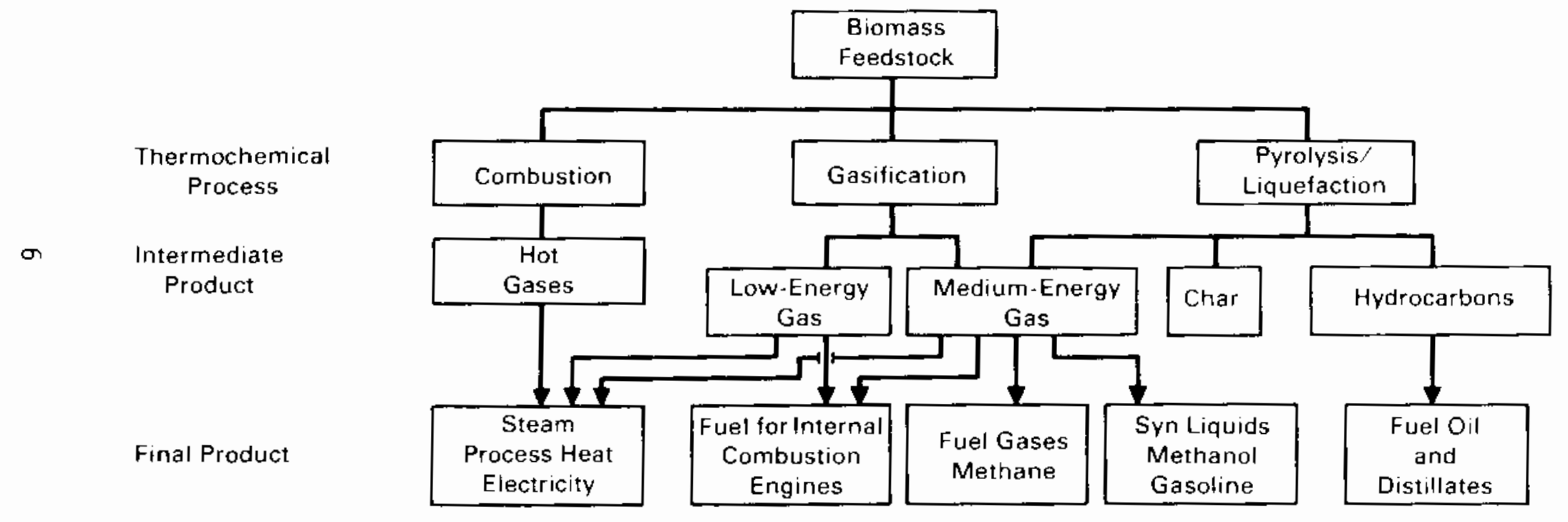

FIGURE 2. Biomass Thermochemical Conversion Processes Produce Versatile Fuels 


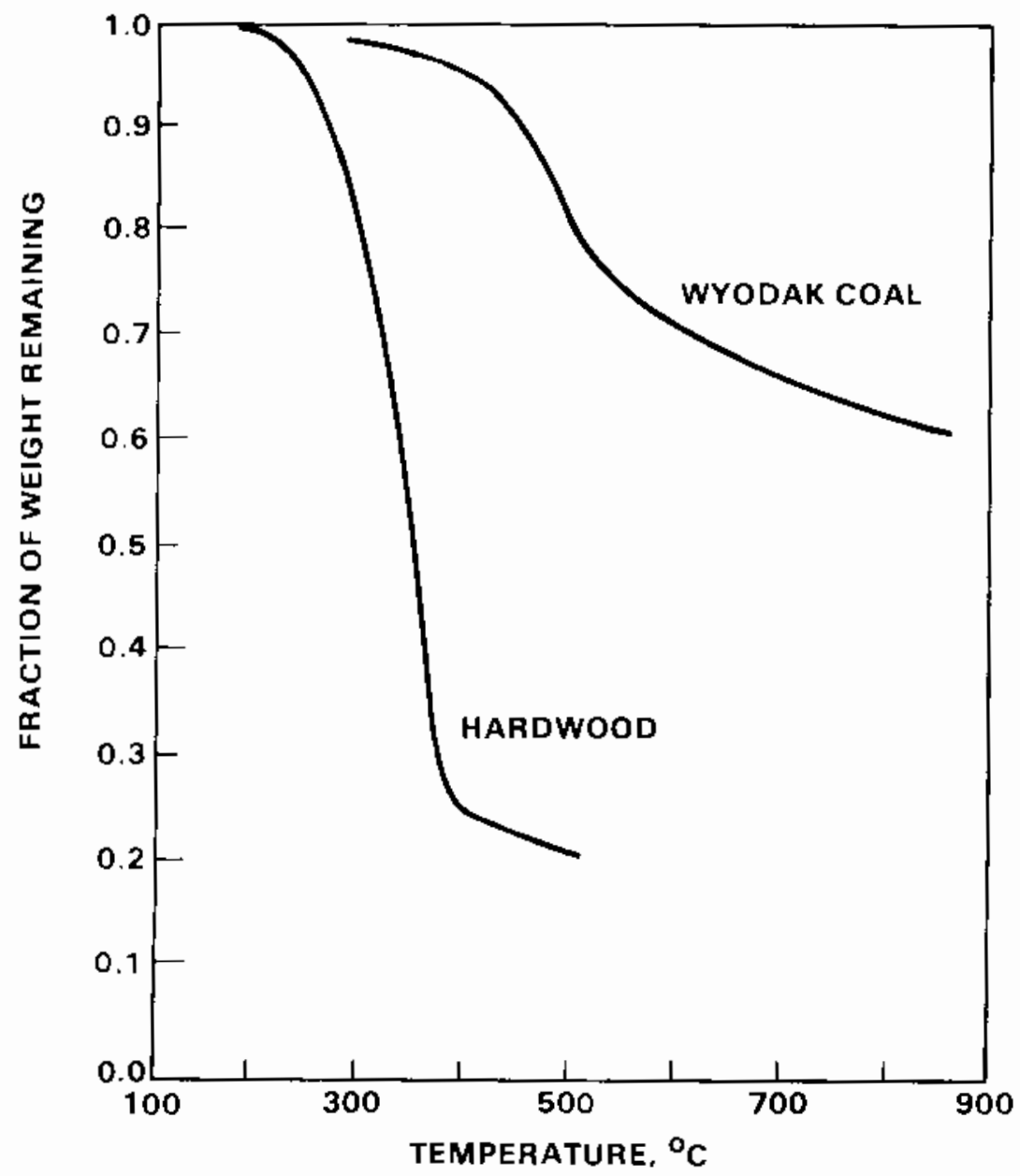

FIGURE 3. Pyrolytic Weight Loss Comparison: Wood Versus Coal Source: Antal, M. J. 1978. Biomass Energy Enhancement A Report to the President's Colncil on Environmental Quality. Princeton University, Princeton, New Jersey.

The combination of these four properties makes it possible to convert biomass feedstocks into gaseous and liquid fuels at faster rates and lower temperatures, and with fewer waste disposal problems, than most coais.

Thus, biomass feedstocks have some potential advantages when compared to fossil feedstocks. However, biomass is a widely distributed resource with a relatively high noisture content. This disadvantage limits the distance over which it can be shipped ecoromically. Developing conversion processes that exploit the unique properties of biomass feedstocks will result in higher conversion rates and lower costs. This will allow biomass-derived gaseous and liquid fuels to be produced competitiveiy in smaller-scale faciljties. 


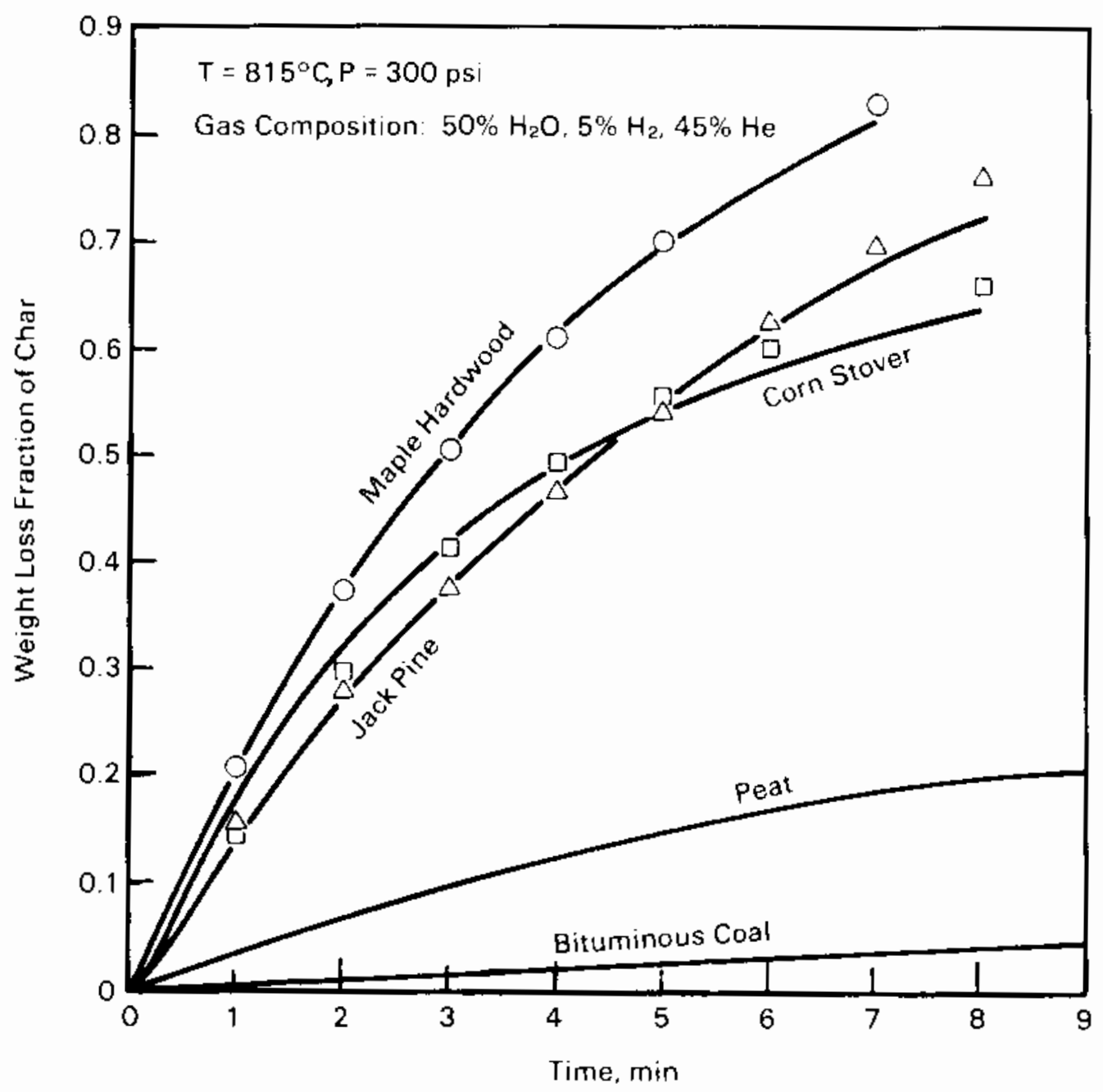

FIGURE 4. Char Reactivity Comparisons: Biomass Feedstocks Versus Peat and Coal

\section{APPROACH}

To achieve its objective and goal, the Thermochemical Conversion Program sponsors research and development activities with high payoff potential. Innovative basic research concepts are initially selected on the basis of prograni research needs, the concepts' potential contribution to advancing the state of the art of biomass conversion, arid the availability of research funds.

Initial research usually consists of determining the technical feasibility of individual concepts in bench-scale experiments. Concepts 
passing the preliminary technical feasibility test are studied in continuous process research units. These smali-scale research units permit further investigation of the concept under realistic conditions in a continuous, dynamic, interactive mode. This research stage allows the evaluation of variations in operating parameters in a continuous process environment and the determination of material and energy balances critical to determining the potential of the process. Individual concepts are then combined into an integrated process. The integrated process is evaluated to estimate process economics at commercial scale. This research approach is shown conceptually in Figure 5.

The interaction between the federal government and private industry in funding research on evolving technologies is shown in Figure 6 . To assure the maximum opportunity for technology transfer to the private sector, industrial interest and involvement is sought at ali stages of research. The governmient role is primarity to explore basic research concepts and establish the technical feasibility of promising technologies. These early stages of research involve risks that are too great and lead times that are too long to be supported by industry. As the data base for evolving technologies becomes better defined, cost-sharing by both the government and private industry becomes more practical. 


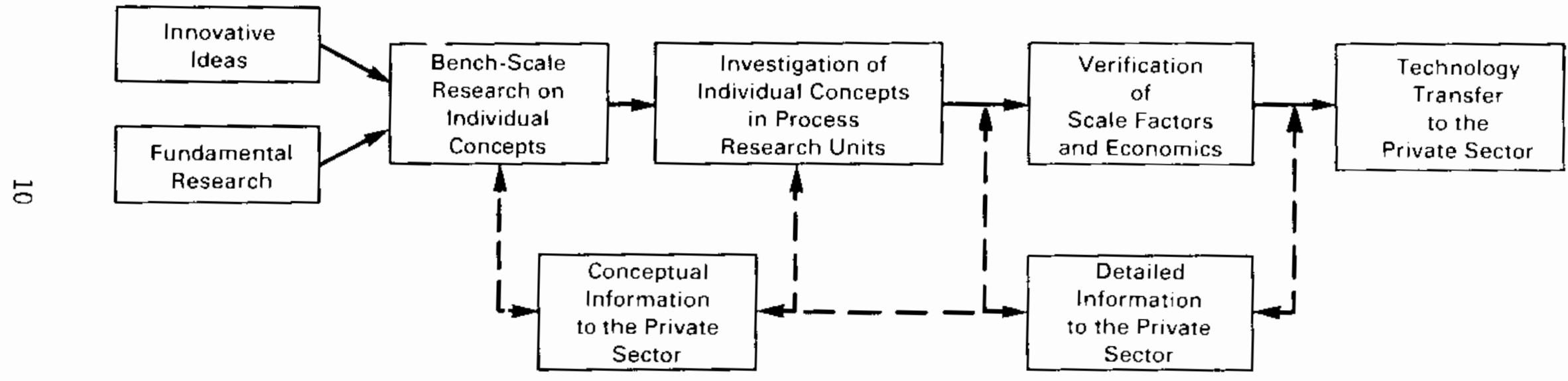

FIGURE 5. Conceptual Approach to Biomass Thermochemical Conversion Research 


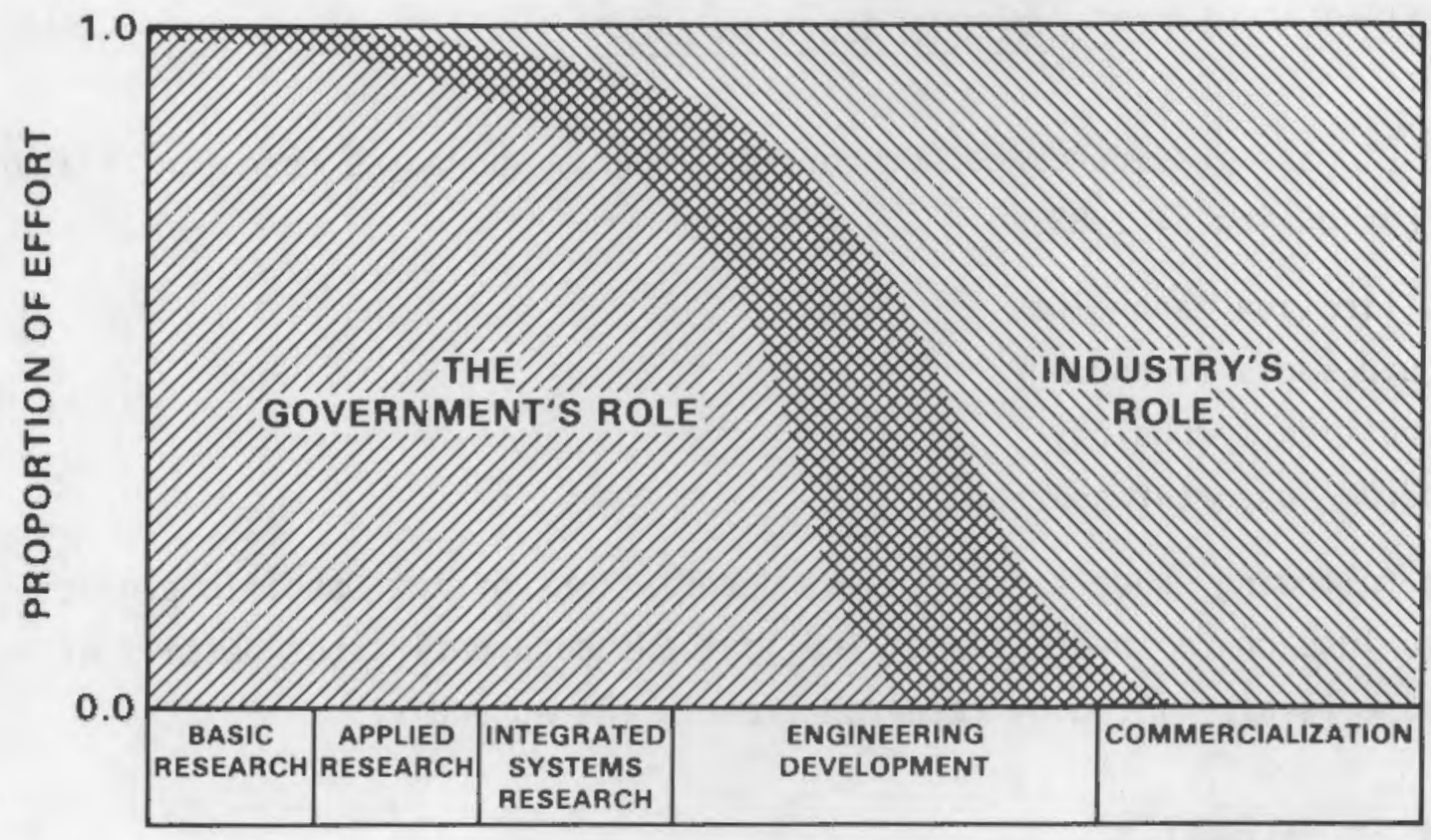

FIGURE 6. Government and Private Industry Interaction in Biomass Thermochemical Conversion Research 


\section{PROGRAM RESEARCH AREAS}

The Biomass Thermochemical Conversion Program sponsored research in four major areas during FY 1983:

1. gasification technology

2. liquid fuels technology

3. combustion technology

4. program support research.

The following subsections present descriptions of the specific projects conducted in each of these areas. Publications documenting the details of these projects are listed by research area in the Appendix.

\section{GASIFICATION TECHNOLOGY}

Gasification of biomass can be achieved by reacting biomass with steam, at moderately high temperatures, to produce a combustible gas containing large quantities of hydrogen and carbon monoxide. Heat is provided to the reactor either by combusting a portion of the biomass with air or oxygen, or by indirectly heating the reactor.

If air is used to heat the gasifier, the nitrogen in the air significantly dilutes the product gas, and a low-Btu gas is produced, as shown in Figure 7. Low-Btu gas typically has a heating value ranging from 90 to $200 \mathrm{Btu} / \mathrm{scf}$. Today, low-Btu gasification of biomass is considered to be a commercial or near-commercial technology. Low-Btu gas can substitute for natural gas and oil to fire boilers, subject to the following limitations:

- Low-Btu gasifiers must be close-coupled to boilers to take advantage of the high temperature of the gas leaving the gasifier.

- Burning low-Btu gas in a boiler designed for oil or natural gas will frequently result in boiler derating unless expensive modifications are made to the boiler.

Low-Btu gas can also be used instead of gasoline and diesel fuel to fuel internal combustion engines, provided that the gas is sufficiently cleaned and cooled. However, the efficiency of the engine will be reduced by about $20 \%$. 


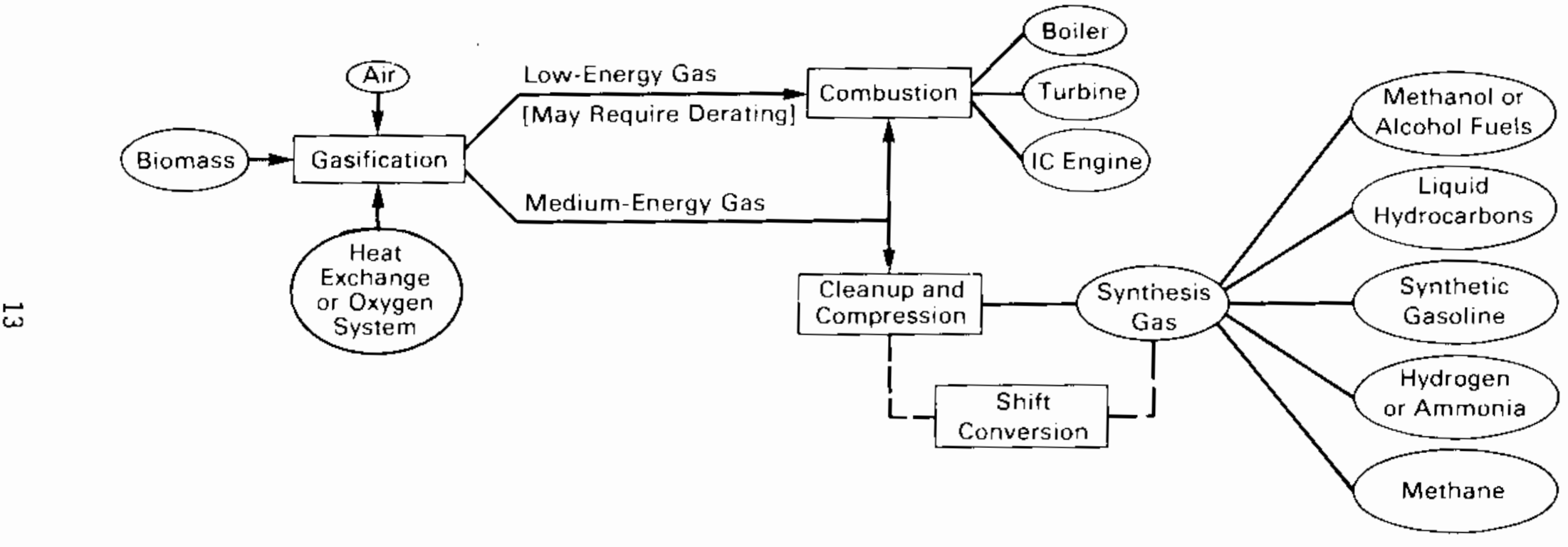

FIGURE 7. Thermochemical Gasification of Biomass 
Although low-Btu gasifiers are commercially available, questions about overall reliability remain.

If nitrogen is eliminated from the product gas of a biomass gasifier by heating it indirectly or with oxygen, a medium-Btu gas can be produced as shown in Figure 7. Medium-Btu gas has a heating value typically ranging from 300 to $600 \mathrm{Btu} / \mathrm{scf}$, and is much more versatile than low-Btu gas.

Because of its higher heating value, it possesses the following advantages over low-Btu gas:

- Medium-Btu gas can be used in nearly all boiler retrofit applications without any boiler derating problems.

- Medium-Btu gas produces a higher flame temperature than low-Btu gas, making it suitable for retrofitting processes where this is a critical factor.

- Medium-Btu gas has two to five times the energy density of low-Btu gas, allowing it to be transported moderate distances by pipeline at a reasonable cost.

- Medium-Btu gas can be used for the synthesis of derived liquid fuels such as methanol, fuel oiis, and gasoline.

Medium-Btu fuel gas can also be produced from coal. The major disadvantage of coal gasification is that coal is not very reactive. Large quantities of oxygen are required to achieve sufficiently high reactor temperatures and reasonable reaction rates. Oxygen plants, however, are very expensive to build and operate. This dictates that medium-Btu coal gasification plants be constructed with very large capacities to take advantage of economies of scale to be competitive.

Because biomass is a distributed resource, transportation costs 1 imit the amount of biomass that can be delivered to a central faciitity. Consequently, biomass gasifiers are limited to a maximum capacity of about 2,000 dry tons of wood per day. Therefore, it is necessary to reduce or eliminate the requirement for oxygen to achieve a cost-effective process at a smailer scale. Fortunately, biomass is much more reactive than coal and can be gasified at 
lower temperatures. Less heat is required for reaction due to the higher volatile content, and the remaining chars are also more reactive, as shown in Figures 3 and 4 . This reduces the oxygen requirement for medium-Btu gasifiers that are directly heated with oxygen. Furthermore, the lower reactor temperatures and heating requirements make it possible to indirectly heat the bjomass in the reactor without using expensive, exotic heat exchanger materials, thereby eliminating the requirement for oxygen. This approach offers the opportunity for significantly reducing gasification costs. In addition, the low sulfur content of most biomass feedstocks makes it possible to gasify biomass in the presence of catalysts without catalyst poisoning problems. The use of catalysts allows for even lower reaction temperatures and makes it possible to adjust the composition of the product gas directiy within the reactor to produce synthesis gases for methane and liquid fuels. The lower sulfur content also el iminates the need for a costly gas cleanup system to remove sulfur from the product gas.

The gasification research projects sponsored by the Biomass Thermochemical Conversion Program are directed primarily toward exploiting the natural advantages of biomass to produce medium-Btu gas. The medium-Btu gas, depending on process concept, can be utilized either as a fuel gas or as a synthesis gas for production of methane or liquid fuels. Research in medium-Btu gasification has focused on using the high reactivity of biomass to reduce or eliminate the requirement for oxygen in the gasifier. Research has also centered on determining the technical feasibility of producing synthesis gas for production of high-value liquid and gaseous fuels. In addition to the prinary emphasis on medium-btu gasification research, the Biomass Thermochemicāl Conversion Program also sponsors a small amount of research on low-Btu gasifiers to improve overall reliability and acceptability of such systems. This research is aimed at methods of increasing gasifier performance and improving product gas cleanup.

The gasification research projects sponsored by the Biomass Thermochemical Conversion Program are shown in Figure 8. A brief description of each project and a discussion of progress during FY 1983 are given below. 


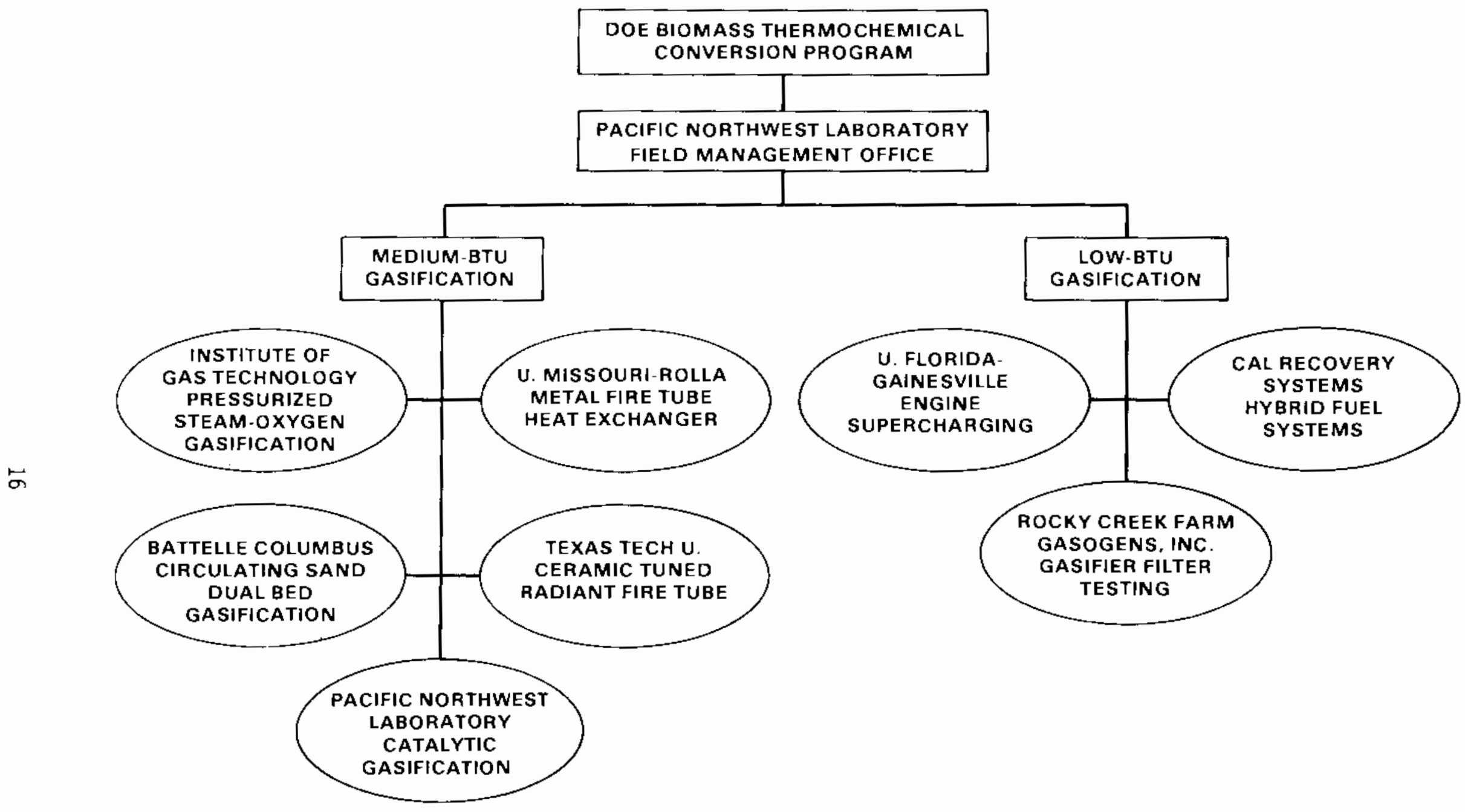

FIGUKE 8. Gasification Research Projects 


\section{Medium-Btu Gasification Research}

BATTELLE-COLUMBUS LABORATORIES (BCL), Columbus, Ohio, is conducting research to determine the feasibility of using a dual bed, entrained gasifier to produce a medium-Btu fuel gas. The concept provides for indirect heating of the gasifier by circulating a low density, hot incandescent sand from a combustor to the gasifier, eliminating the need for using purified oxygen. As shown in Figure 9, the entrained sand and any char leaving the gasifier is separated from the product gas in a cyclone. Both the sand and char are transferred to an entrained bed combustor where the char is burned with air. The sand is heated to a high temperature and recirculated back to the gasifier. The apparatus is shown photographicaliy in Figure 10; the feeder is in the foreground with the insulated gasifier behind it.

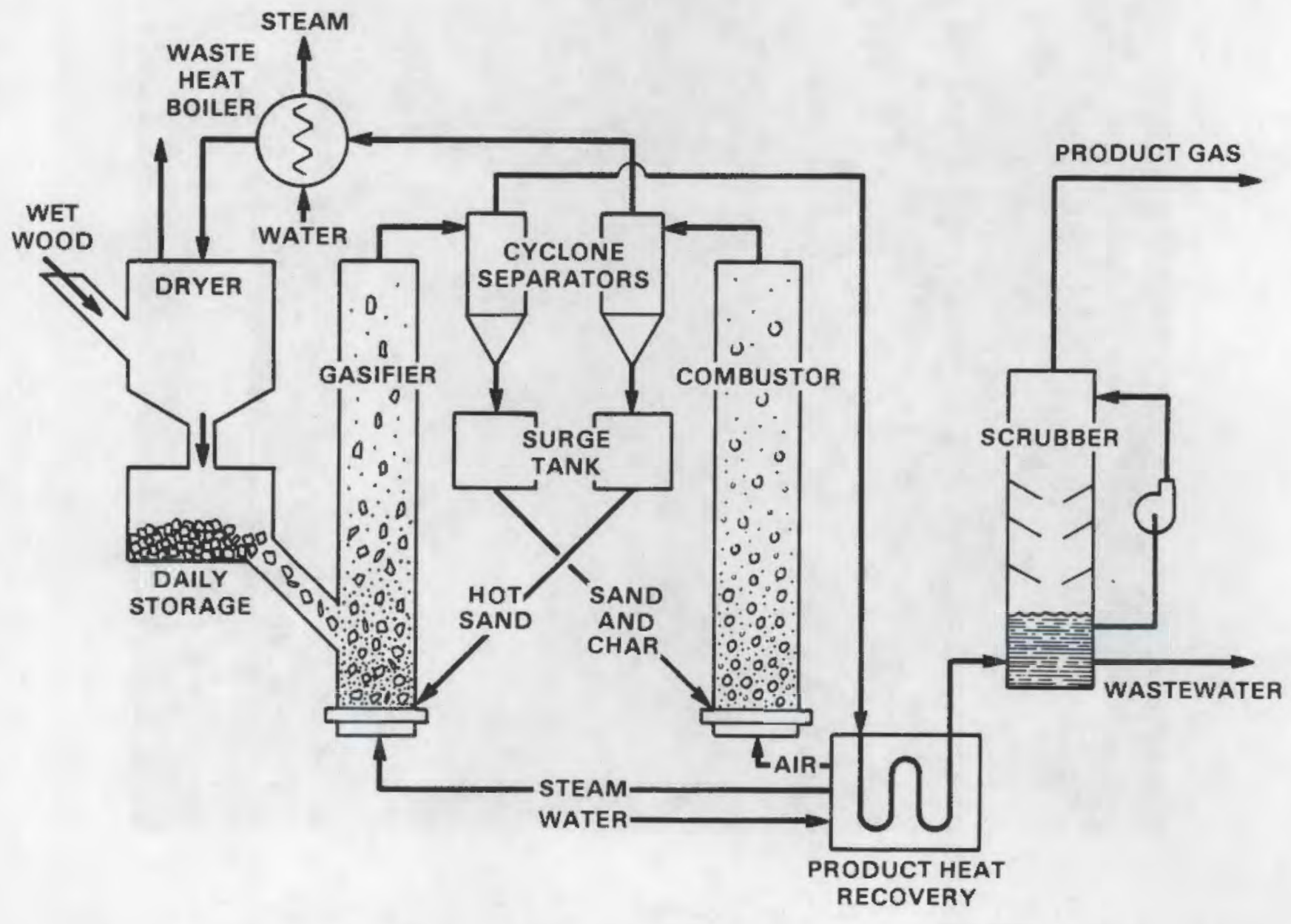

FIGURE 9. Battelle-Columbus Dual Bed, Entrained Gasifier Process 


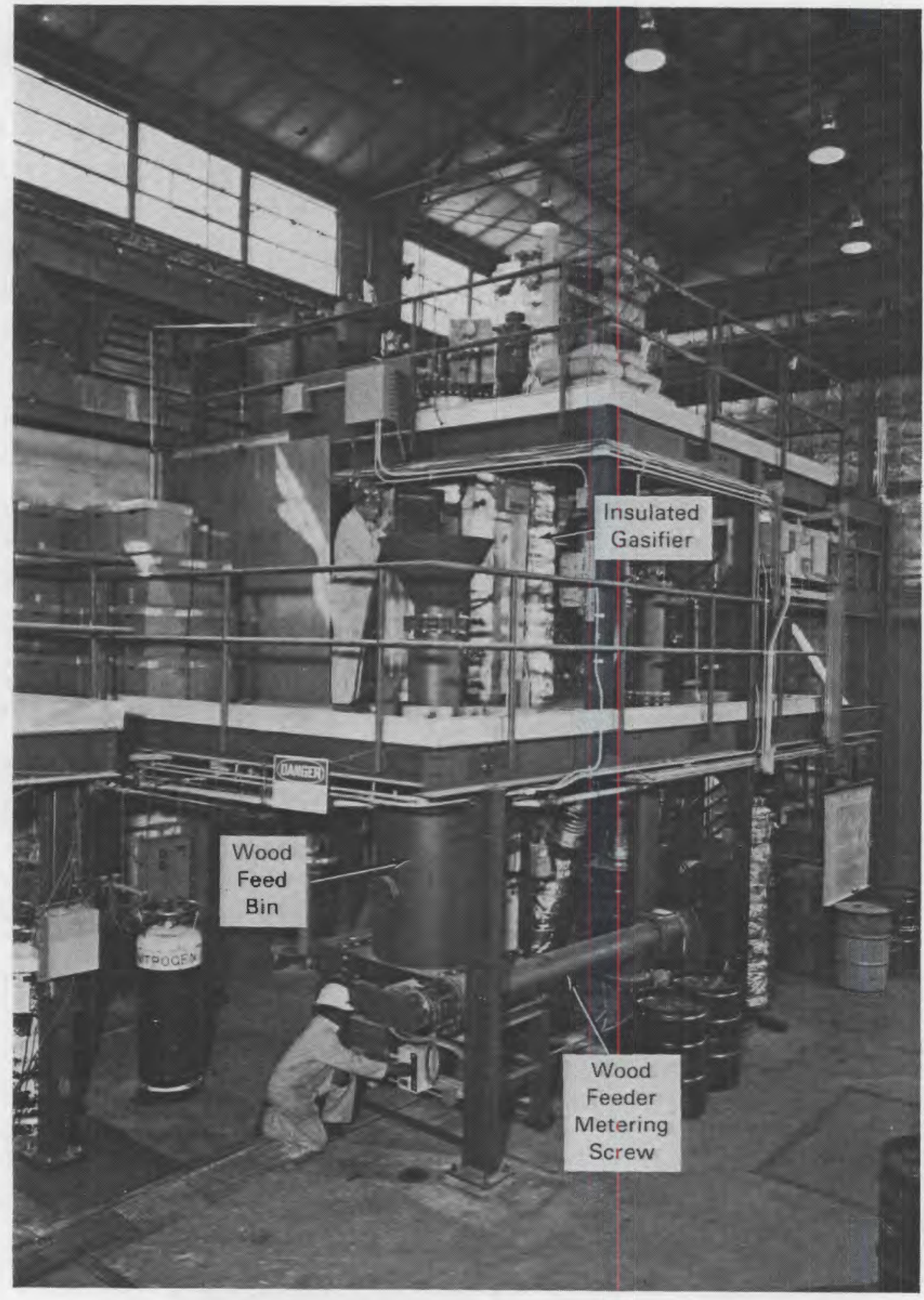

FIGURE 10. Eàttelle-Columbus Dual Bed, Entrained Gasifier 
In the previous research using a 6-in. diameter gasifier, $B C L$ successfully produced a medium-Btu fuel gas with a heating value of about 475 Btu/scf using both wood chips and coarsely shredded bark. As shown in Figure 11 , this heating value did not vary significantly for feedstocks containing from $8 \%$ to $40 \%$ moisture on a wet basis. Gasifier throughputs of up to 1800 $\mathrm{lb} / \mathrm{hr} / \mathrm{ft}^{2}$ were achieved.

In 1983, the gasifier was modified from 6 in. to $10 \mathrm{in}$. in diameter to more fully examine the critical operating parameters. The modified reactor was operated successfully, obtaining even higher carbon conversions under similar operating conditions than were obtained in the smaller unit. Feed rates of about $1100 \mathrm{lb} / \mathrm{hr}\left(2000 \mathrm{lb} / \mathrm{hr} / \mathrm{ft}^{2}\right)$ were also achieved.

THE INSTITUTE OF GAS TECHNOLOGY (IGT), Chicago, IIlinois, is conducting research to determine the actual oxygen requirements for gasifying biomass to produce a medium-Btu gas. A 12-in. diameter fluidized bed research gasifier

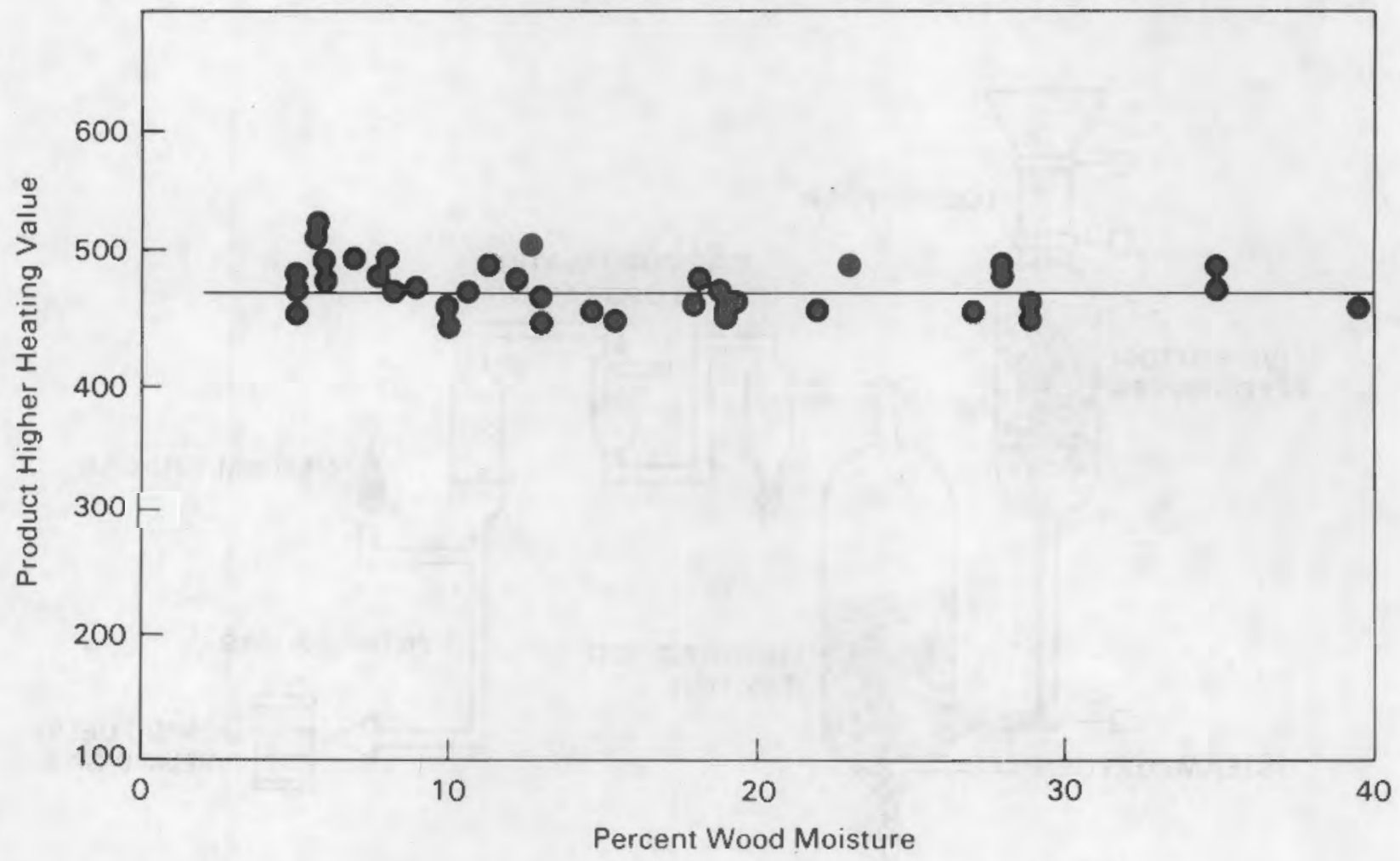

FIGURE 11. Product Gas Heating Value Versus Feedstock Moisture 
was designed to explore the effects of pressure (up to 500 psia), reactor bed height, feed positions, feedstock type, and temperature on product gas yield and composition. The gasifier is shown schematically in Figure 12.

During 1983, construction of the fluidized bed gasifier was completed and system shakedown operations began. Initial results showed that the system can gasify wood at feed rates up to $270 \mathrm{lb} / \mathrm{hr}$ and pressures up to $270 \mathrm{psia}$. This system will ultimately be tested at feed rates up to $1000 \mathrm{lb} / \mathrm{hr}$ at pressures exceeding 300 psia. Research using this reactor system will be performed to determine the optimal oxygen and steam requirements for producing synthesis gases.

THE UNIVERSITY OF MISSOURI, Rolla, Missouri, is investigating the technical feasibility of using metal fire-tubes to provide heat indirectly to a fluidized bed gasifier. In the conceptual design, a portion of the feedstock or product gas would be burned to provide heat for the fire-tube heat exchanger. The concept eliminates the need for pure oxygen in the gasifier. As a result,

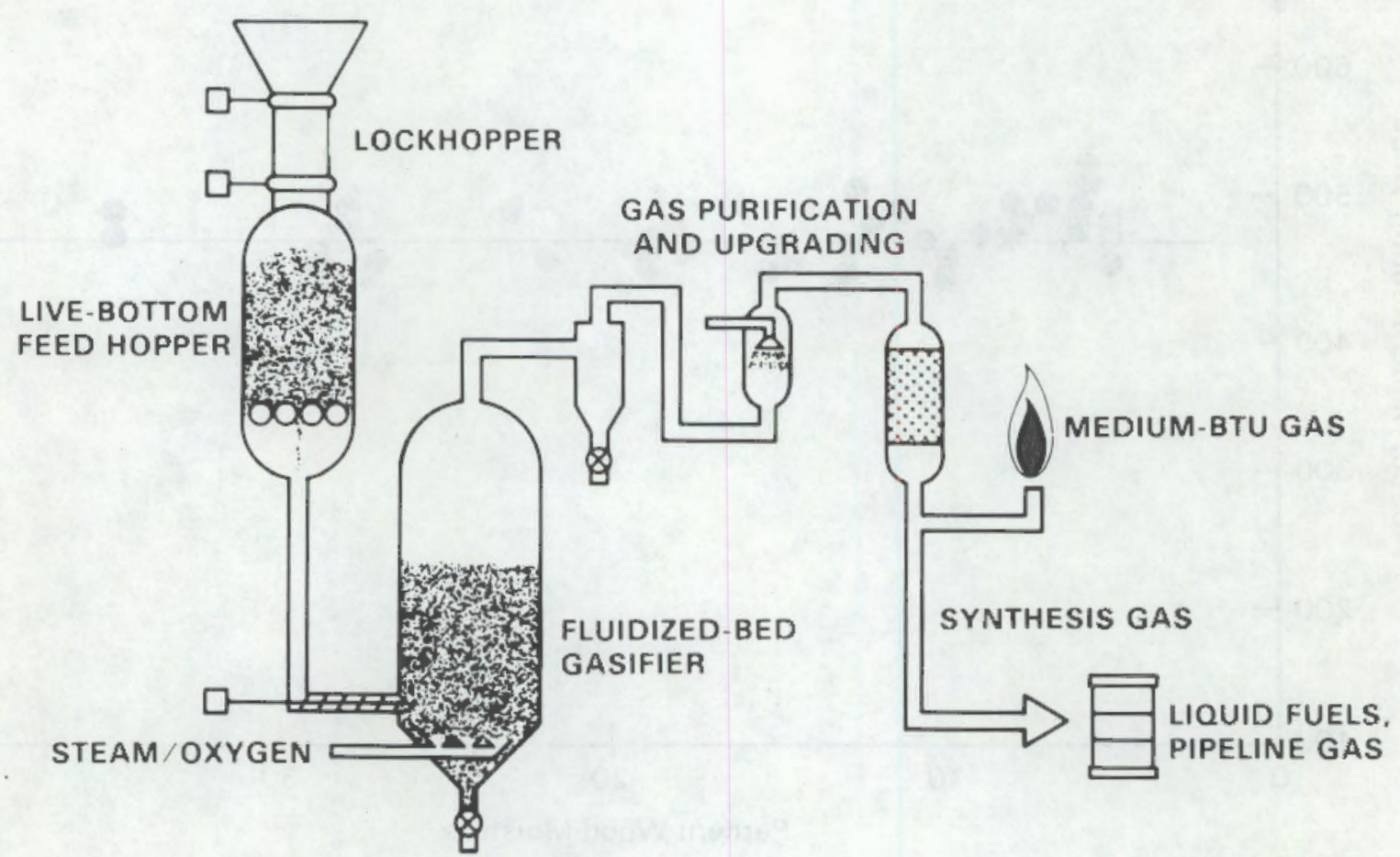

FIGURE 12. Institute of Gas Technology Fluidized Bed Gasifier 
catalysts could potentially be used in the fluidized bed without harmful oxidation.

During 1983, the university completed construction of a 20-in. gasifier and began shakedown operation. The configuration selected for actual testing uses thirty $1-i n$. diameter U-tubes spaced on a 2-in. pitch. One view of the reactor is shown in Figure 13. The system has been operated at feed rates up to $400 \mathrm{lb} / \mathrm{hr}$ ( $10 \%$ moisture wood) and temperatures up to $1365^{\circ} \mathrm{F}$. Future research will determine the optimal process conditions for producing medium-Btu gas and will determine critical design parameters for the heat exchanger.

TEXAS TECH UNIVERSITY, Lubbock, Texas, is investigating the technical feasibility of enhancing the radiant heat transfer capabilities of indirectly heated fluidized bed gasifiers. The concept uses ceramic heat exchanger fire-tubes doped with rare-earth metals to match the wavelength of the heat radiated by the tubes to the absorption wavelengths of the biomass. By doping the ceramic tubes to emit radiant heat at selected wavelengths, a large portion of the radiant energy will be absorbed by the biomass, increasing the rate of devolatilization and gasification. Fundamental research at Texas Tech University has been directed toward developing a predictive mathematical model for radiant heat transfer in an absorbing fluidized bed of biomass particles. A small single-tube reactor was completed during 1983, and heat transfer measurements were made for correlation with the theoretical model. Results will be used to design a small multitube reactor for additional research.

PACIFIC NORTHWEST LABORATORY (PNL), Richland, Washington, is studying the technical feasibility of producing tailored synthesis gas in a medium-Btu gasifier. Synthesis gases for the production of liquid fuels such as methanol require relatively pure mixtures of hydrogen and carbon monoxide with a molecular ratio of 2.0 to 2.5 moles of hydrogen per mole of carbon monoxide. Research at PNL is examining the feasibility of producing synthesis gases tailored to specific needs directly in the gasifier. This concept uses a catalyst in a fluidized bed gasifier to produce hydrogen and carbon monoxide products in ratios of 2.0 or greater and is shown schematically in Figure 14 . 

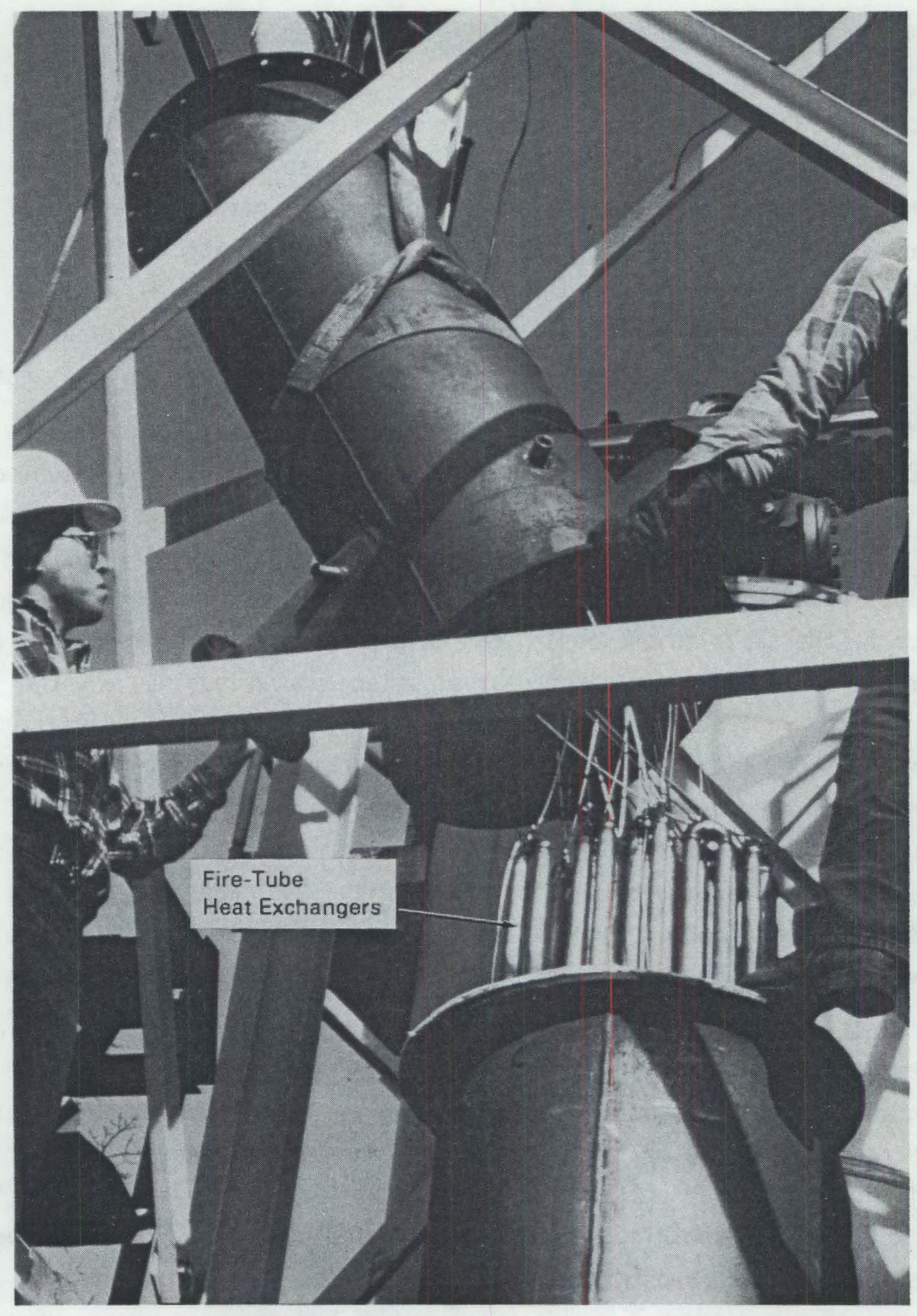

FIGURE 13. Metal Fire-Tube Heat Exchangers Inside Fluidized Bed Gasifier at University of Missouri-Rolla 
During 1983, laboratory studies were conducted to determine the roles of primary and secondary catalysts in the gasification process. Alkali carbonate catalysts (primary catalysts) increased both the production of char during devolatilization and the rates of the subsequent steam gasification of that char. The primary catalysts also significantly reduced the production of tars and condensible organics at $750^{\circ} \mathrm{C}$. Studies of supported reforming catalysts (secondary catalysts) with model compounds showed that catalyst deactiviation due to carbon deposition was more pronounced with heavier hydrocarbons. These data will be used in fluidized bed gasification experiments to determine optimal reactor conditions for catalytically producing synthesis gas.

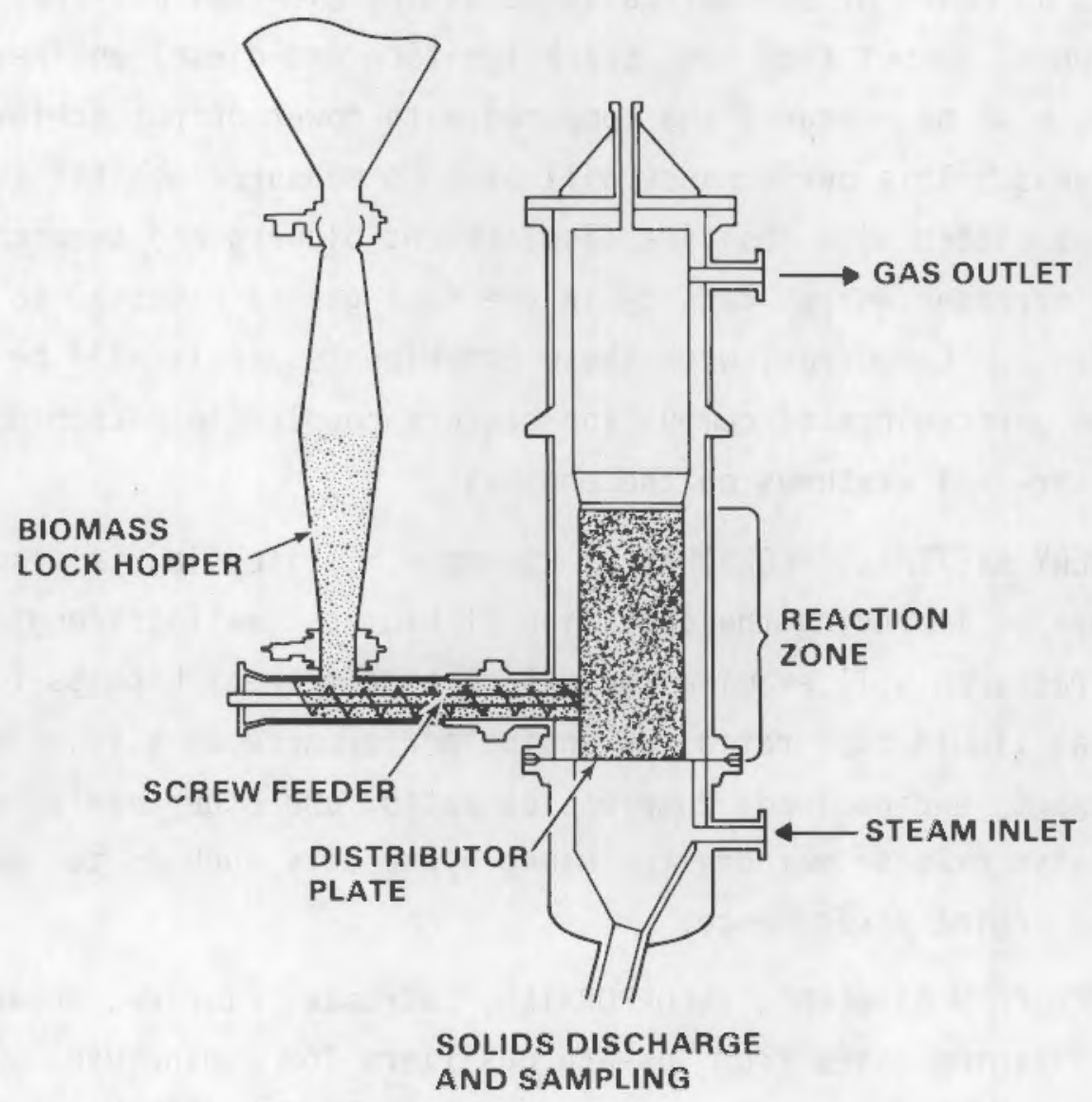

FIGURE 14. Pacific Northwest Laboratory Catalytic, Fluidized Bed Gasifier 
Low-Btu Gasification Research

In addition to the primary goal of producing a technology data base for medium-Btu gasification, the Biomass Thermochemical Conversion Program conducted research on low-Btu gasification in fiscal year 1983. The main goal of this research has been to improve the overall reliability of this technology option.

THE UNIVERSITY OF FLORIDA, Gainesville, Florida, began research to enhance the performance of engines fueled with producer gas. Project goals are to evaluate the use of positive displacement and turbine superchargers for increasing the power output of engines operated on low-Btu gas and to evaluate microprocessors as means of automatically adjusting air-fuel mixtures in such engines. The power output from both spark ignition and diesel engines operated on producer gas will be measured and compared with power output achieved using conventional fuels. This performance will also be measured against that of the same engines fitted with positive displacement blowers and turbocharging systems. The increased energy density in the fuel gas is expected to enhance engine performance. Concurrent with these experiments, tests will be conducted to evaluate the performance of combustion sensors coupled to microprocessors for adjusting air-fuel mixtures on the engines.

CAL RECOVERY SYSTEMS, INCORPORATED, Richmond, California, is also working to identify ways of improving the operation of biomass gasifiers/engine systems. The research will examine the effect of different biomass fuel gas/conventional liquid fuel ratios on engine performance as a function of total energy input, engine load, compression ratio, and other variables. The research will also examine methods for using byproducts such as tar and waste heat to improve engine performance.

ROCKY CREEK FARM GASOGENS, INCORPORATED, LaCrosse, Florida, began research on methods of cleaning gases from low-Btu gasifiers for engine use. This research uses a cowndraft gasifier mounted on a 40-hp John Deere tractor for a combination of laboratory research and field testing. Laboratory research will include particulate measurements as a function of gas cleanup method, fuel characteristics, and other factors. Field testing of the unit will also 
be performed to provide operational data on the acceptability of the producer gas-fueled tractor, including identification of best cleanup methods, operatorassociated problems, and related factors.

\section{LIQUID FUELS TECHNOLOGY}

The Biomass Thermochemical Conversion Program is also conducting research on the production of liquid fuels from biomass. Liquid fuels have several advantages over the biomass resource itself. Perhaps most important, liquid fuels have a higher energy density. This allows the liquid product to be transported more economically and to be more easily stored. Liquid fueis also match existing end-use patterns, particularly by the transportation sector. The goal of the liquid fuels research sponsored by the Biomass Thermochemical Conversion Program is to provide the technology base for producing economical liquids that are compatible with existing hydrocarbon fuels. To meet this goal, the program is conducting research directed at:

- identifying reaction pathways and methods for producing high value liquid fuels

- improving yields and quality of liquid fuels

- producing economically competitive fuels.

As shown in Figure 15, the research is divided into two primary areas including pyrolysis and direct liquefaction. The differences in these approaches make it possible to generate a variety of fuels ranging from fuel oil substitutes to olefinic/aromatic hydrocarbons. The ability to produce a variety of fueis is important in meeting the wide range of demands from the liquid fuel market. These two research areas and the specific projects in each are described in detail below.

Pyrolys is

Pyrolysis refers to the heating of biomass in the absence of air. Traditionally, pyrolysis has been used to produce charcoal. Conventional pyrolysis typically produces about one-third each gases, pyrolysis oils, and char. The process is inefficient because large quantities of low value 


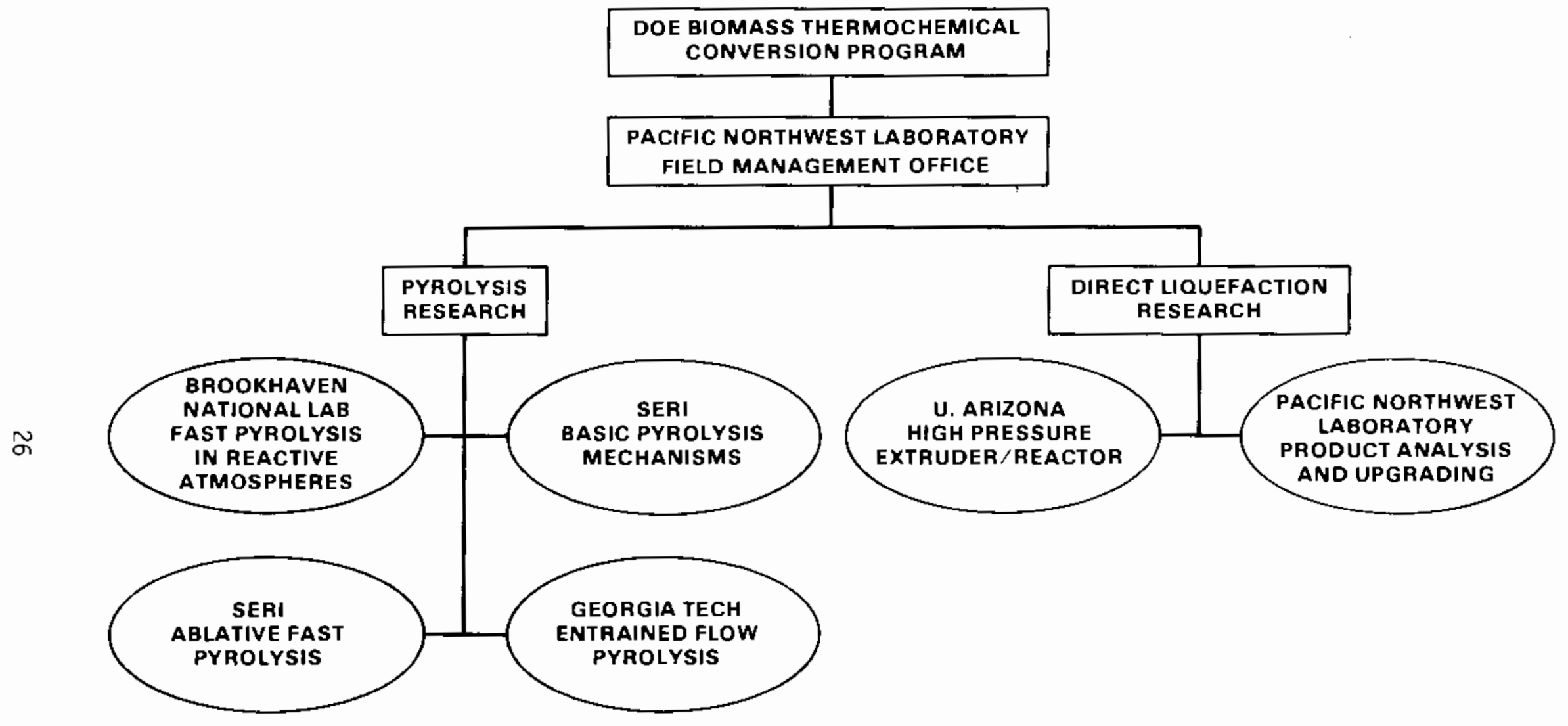

FIGURE 15. Liquid Fuels Research Projects 
liquids and gases are formed in addition to desired solid products. Batchwise, often primitive, conversion unjts have also added to the inefficiency of conventional pyrolysis processes.

In recent years, the concept of rapid pyrolysis has emerged as a promising alternative for producing liquid fuels. Using rapid heating rates, yields of gases and 1 iquids as high as $95 \%$ can be produced. These products contain up to about $20 \%$ high value olefinic products such as ethylene and BTX (benzene, toluene, and xylene), and are potentially useful as fuels and octane enhancers.

The pyrolysis research sponsored by the Thermochemical Conversion Program is directed toward capitalizing on these results by:

- using extremely fast pyrolysis to maximize yields of high value olefins and aromatics

- improving the yields of fast pyrolysis reactions by using reactive atmospheres

- using fast pyrolysis to produce high yields of low-cost fuel oil substitutes.

Four research projects are current?y being conducted in fast pyrolysis. THE SOLAR ENERGY RESEARCH INSTITUTE (SERI), Golden, colorado, is conducting two projects to investigate the fast pyrolysis of biomass. In the first project, basic research examining the mechanisms occurring in fast pyrolysis is underway. Using a molecular beam mass spectrometer, a detajled picture of the individual, sequential reaction steps occurring during fast pyrolysis is being developed by measuring the change in product spectrum occurring during millisecond intervals. Although there are many possible mechanisms for producing low vaiue char and tars, the production of high-value products appears to be limited to conditions of high heating rates and relatively high temperatures $\left(500\right.$ to $\left.700^{\circ} \mathrm{C}\right)$. Representative competing pyrolys is reaction pathways are shown in Figure 16. 


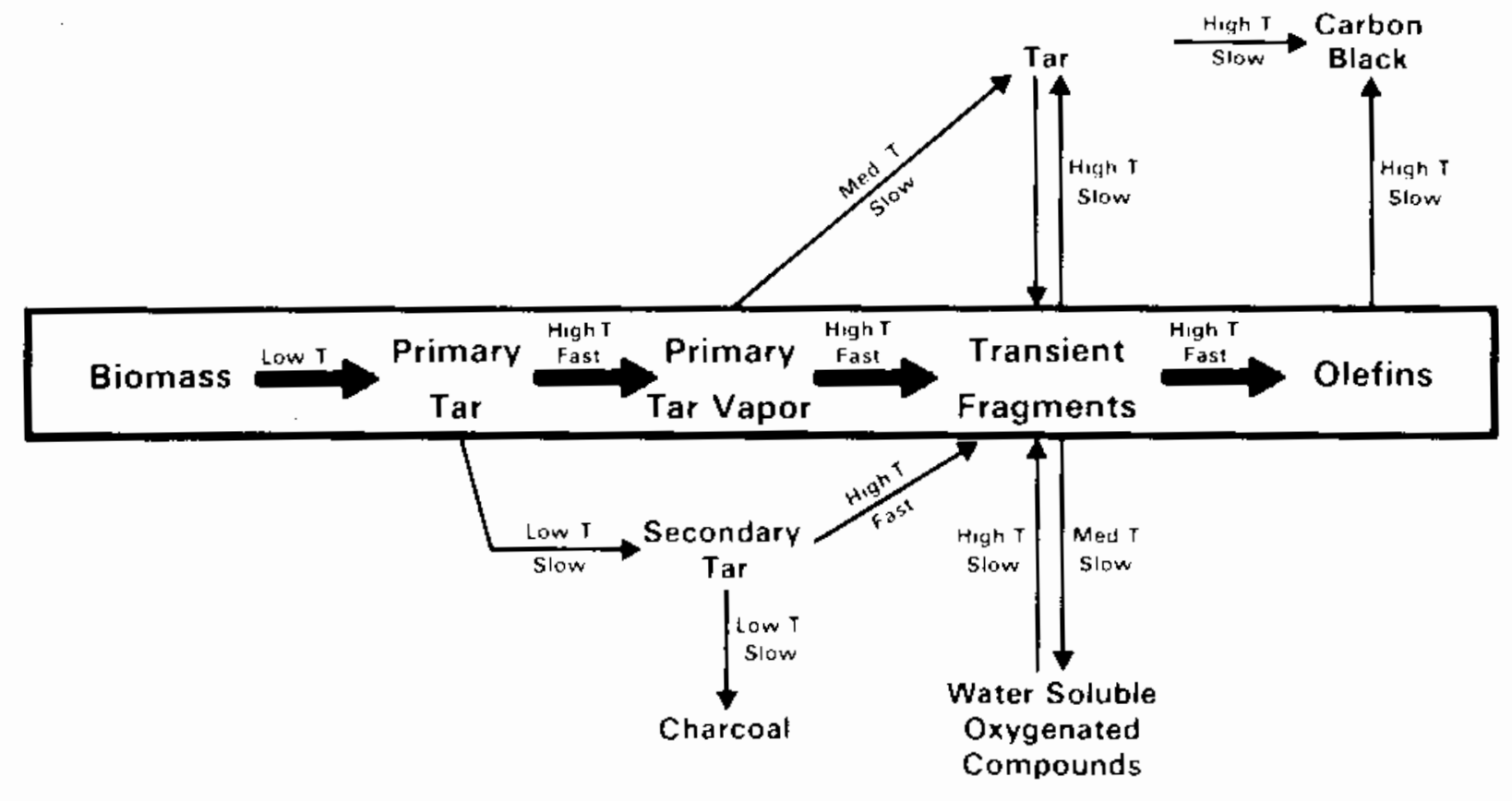

FIGURE 16. Competing Reactions During Bioniass Pyrolysis

During 1983, SERI examined both the primary and secondary cracking patterns for cellulose and lignins and correlated the results with whole wood products. The researchers have also developed a method for quickly comparing biomass liquids and tars by establishing a mass spectrometric "fingerprint" of primary pyrolysis products. The technique serves as a useful qualitative method for comparing products from various types of processes.

The second project at SERI is investigating the use of a unique abiative reactor for fast pyrolysis. The objective of this work is to maximize yields of high-vaiue olefins and other products such as benzene, toluene, and xylene, which are furmed under conditions of very rapid pyrolysis. The goal of this research is to determine how to obtain the high heat fluxes needed for rapid pyrolysis and to investigate fundamental reaction mechanisms. In ablative pyrolysis of bionass, particles are heated by being forced against a hot reactor wall. Contact of the biomass with the reactor surface converts the biomass into a liquid layer, which is subsequently vaporized. Heatup rates as high as $500,000^{\circ} \mathrm{C} / \mathrm{sec}$ can be obtained at the sample surface. A scheratic of the reactor system is shown in Figure 17 . In addition to the olefins, carbon monoxide and hydrogen are aiso produced and could be used for methanol synthesis. 


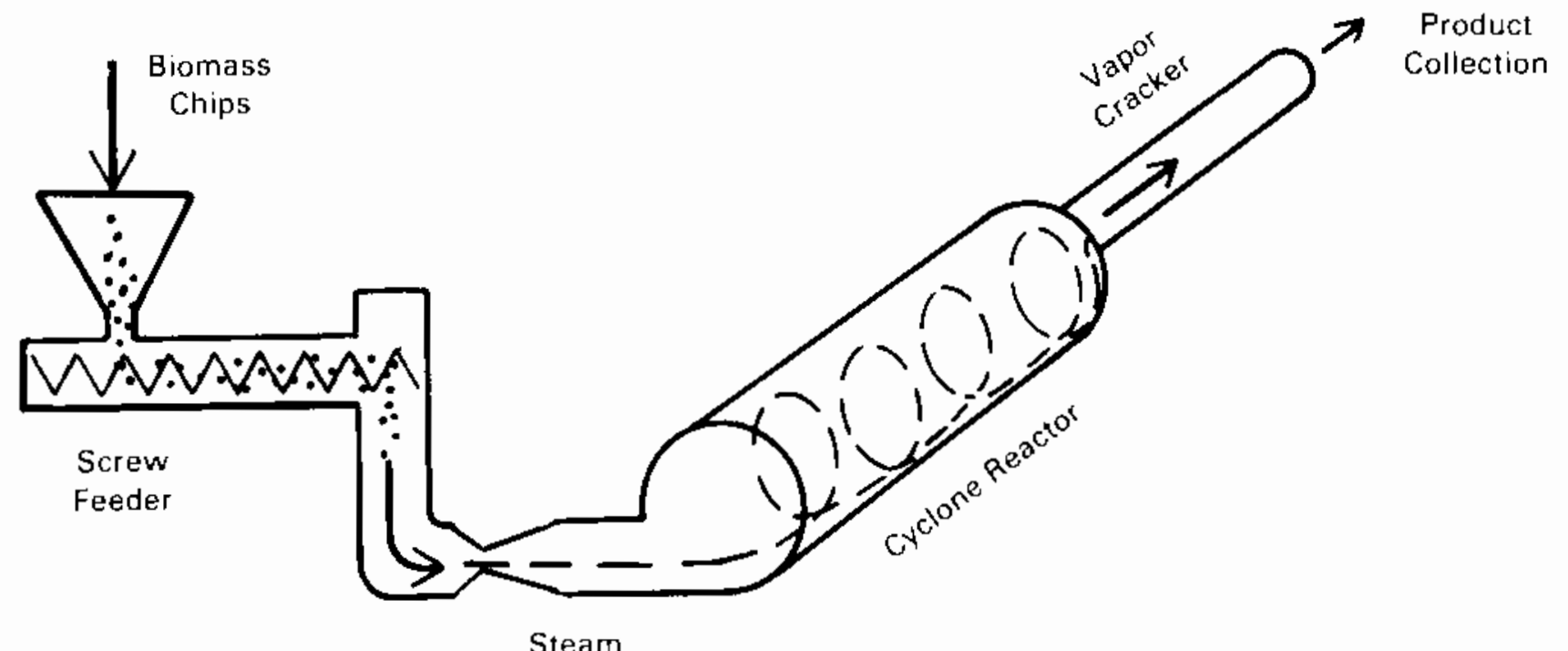

Steam

Ejector

FIGURE 17. Rapid Pyrolysis Research Reactor at Solar Energy Research Institute

During 1983, SERI developed a theoretical model to predict reaction behavior under these conditions. The model uses Arrhenius rate parameters for approximately 10 reactions to predict global behavior. The model predicts that pyrolysis begins at about $350^{\circ} \mathrm{C}$ and that vapor cracking begins at about $625^{\circ} \mathrm{C}$. However, at higher temperatures around $750^{\circ} \mathrm{C}$, the rates begin to favor char formation. Thus, a temperature window may exist for maximum production of high-value products. Correlation of these theoretical results with experimental results is proceeding.

Research at BROOKHAVEN NATIONAL LABORATORY, Upton, New York, is investigating the effect of conducting rapid pyrolysis in the presence of reactive atmospheres. Using a bench-scale, entrained downflow reactor, biomass is pyrolyzed at pressures of 50 to 500 psi and temperatures of 800 to $1000^{\circ} \mathrm{C}$. During 1983, research focused on reaction of biomass in a methane atmosphere (methanopyrolysis). Although the product spectra of wood pyrolyzed in either methane or helium are simitar at moderate temperatures $\left(800^{\circ} \mathrm{C}\right)$, significant differences occur at higher temperatures, as seen in Figure 18. At $1000^{\circ} \mathrm{C}$, the yields of ethylene and olefins from the methane system increase 


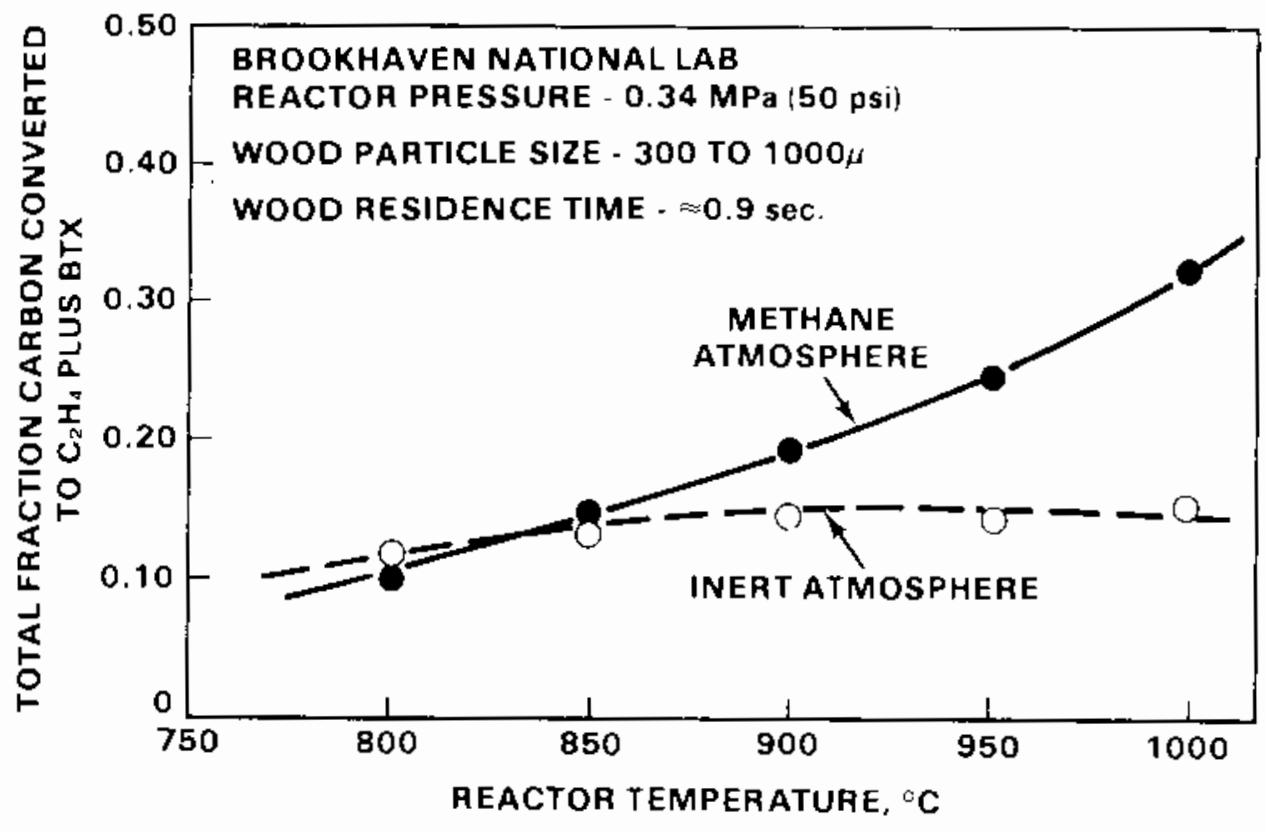

FIGURE 18. Comparison of Biomass Pyrolysis Products in Inert and Methane Atmospheres

rapidly to more than double those in the inert atmosphere. Extensive investigation during 1983 has shown that the methane is not reactive under identical conditions when biomass is absent. These results suggest that it may be possible to produce high yields of valuable olefinic products under much less rapid heating rates when reaction conditions are carefully selected. Further studies on these types of systems are continuing.

Under less rapid heating rates, biomass pyrolysis produces high yields of liquid products that could potentially be used as fuel oil substitutes. GEORGIA TECH, Atlanta, Georgia, is conducting research with an entrained flow pyrolysis unit with the goal of generating high yields of liquids at low cost. During 1983, Georgia Tech finished construction of an entrained flow pyrolys is reactor, shown schematically in Figure 19. The system consists of an upflow, entrained pyrolysis reactor and an oil recovery system that allows partial on-stream fractionation of the product. Initial experimental operation of the unit, shown in Figure 20, began recently. Reaction temperatures of 450 to $550^{\circ} \mathrm{C}$ have been examined and wood feed rates up to $85 \mathrm{lb} / \mathrm{hr}$ have been obtained. Preliminary results indicate that greater than $41 \%$ oils by weight (moisture- 


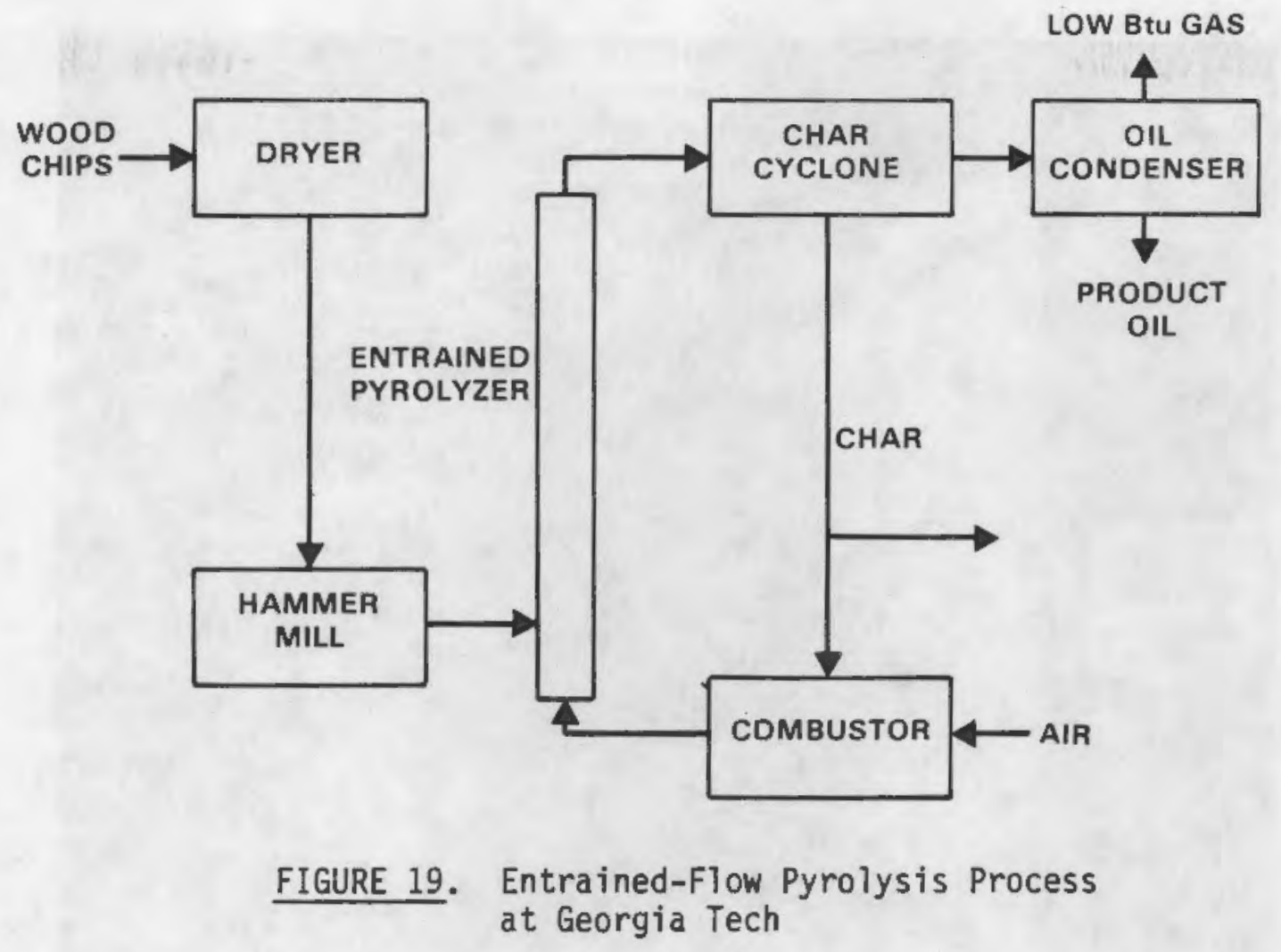

free basis) can be obtained. This represents nearly double the yields from conventional pyrolysis systems. Results from related research indicate that yields as high as $60 \%$ by weight may be obtained as operating parameters are optimized.

\section{Direct Liquefaction}

In addition to research on advanced pyrolysis concepts, the Thermochemical Conversion Program is sponsoring research on biomass direct liquefaction. Direct liquefaction is defined in the broadest sense as any thermochemical conversion process that produces liquid products from biomass feedstock without going through a separate intermediate gas phase. Over the past few years, however, this terminology has become more narrowly defined to describe a particular type of reductive liquefaction. Specifically, biomass slurries are heated to moderate temperatures at high pressures with a catalyst in a reducing atmosphere of carbon monoxide and hydrogen. The goal of this direct liquefaction research is to produce liquid products that can be used as substitutes for Nos. 2 and 6 fuel oils, and distillate fractions that can be 


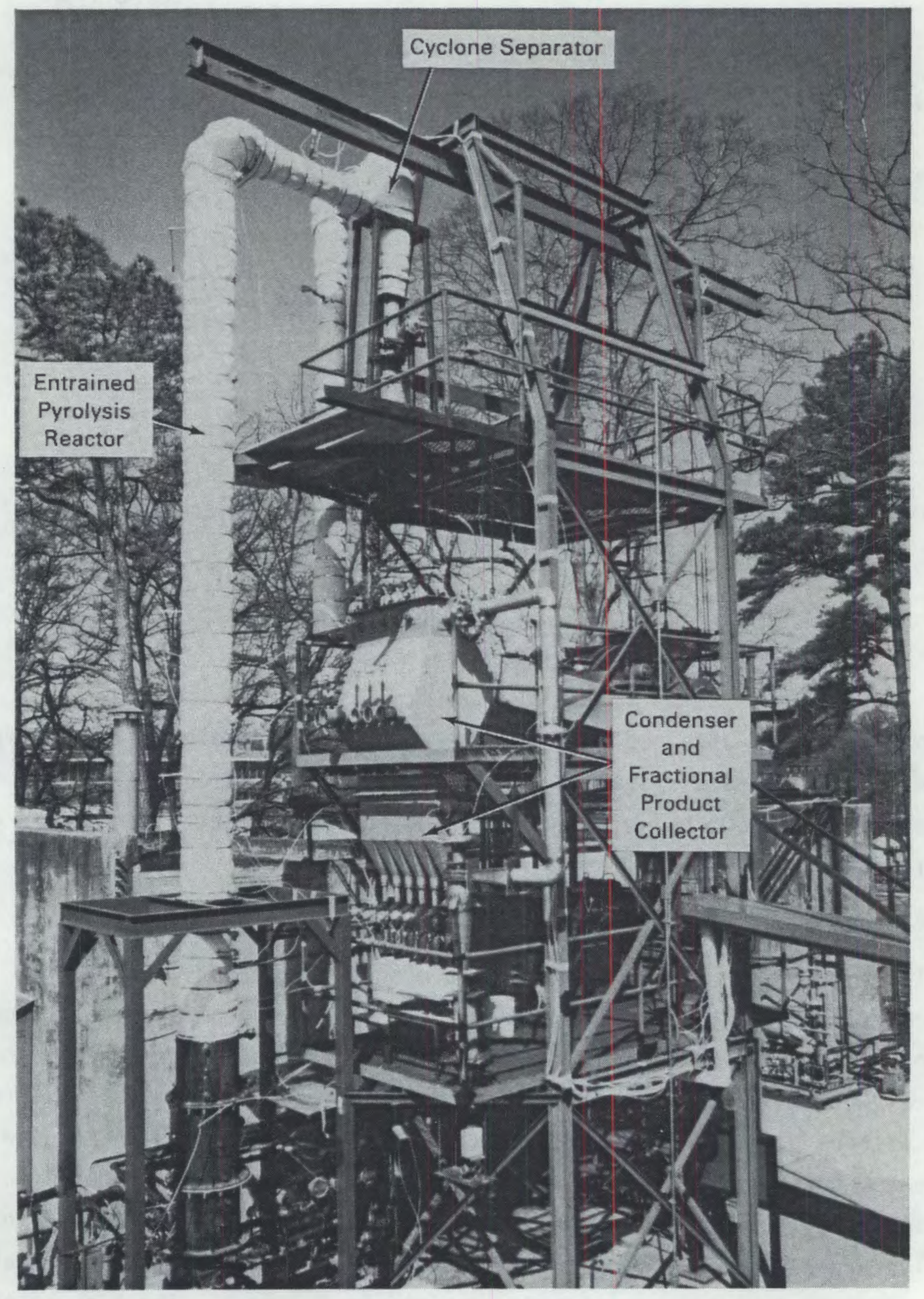

FIGURE 20. Georgia Tech Pyrolysis Unit 
used for diesel fuels, octane enhancers, and other related applications.

Direct liquefaction research at this time is based primariiy on a concept first proposed by the Pittsburgh Energy Research Center (PERC). In this concept, biomass is mixed with recycle wood oil and sodium carbonate catalyst along with a $\mathrm{H}_{2} / \mathrm{CO}$ reducing gas of mixture. The mixture is injected into a high-pressure vessel (3000 psi) and heated to about $350^{\circ} \mathrm{C}$. The product stream is cooled and flashed into a pressure let-down vessel. The ojl phase product is withdrawn and part of it is recycled for use as slurry medium.

During 1981, the PERC process was tested in a DOE research facility located at Albany, Oregon. These tests confirned the technical feasibility of this approach. Over 11,000 pounds of oil resembling No. 6 fuel oil were produced in one run alone. However, the results indicated that the process is not now economically competitive, partiy because of the large recycle oil requirenent. The Thermochemical Conversion Program is attempting to improve the competitiveness of direct liquefaction by:

- improving the economics of direct liquefaction through the use of increased feedstock slurry concentrations

- improving product quality by reducing oxygen content and molecular weight.

THE UNIVERSITY OF ARIZONA, Tucson, Arizona, is conducting research on an advanced concept for direct liquefaction that woulo use very concentrated biomass slurries. The goal of this work has been to use a polymer extruder as a slurry feeding/pumping device. The modified extruder/feeder system is capable of handling siurries as concentrated as $60 \%$ wood solids in biomass oil. Conventional systems, by comparison, typically cannot handle slurries containing over about 20\% wood. Currently a static mixer reactor is being added to the feeder to create an integrated reactor system. The static mixer, similar to those used for mixing viscous polymer solutions, is expected to allow adequate mixing and agitation of the viscous slurries. A schematic diagram of the extruder/reactor is shown in Figure 21. Startup operation of the integrated extruder/static mixer reactor is expected in 1984. 


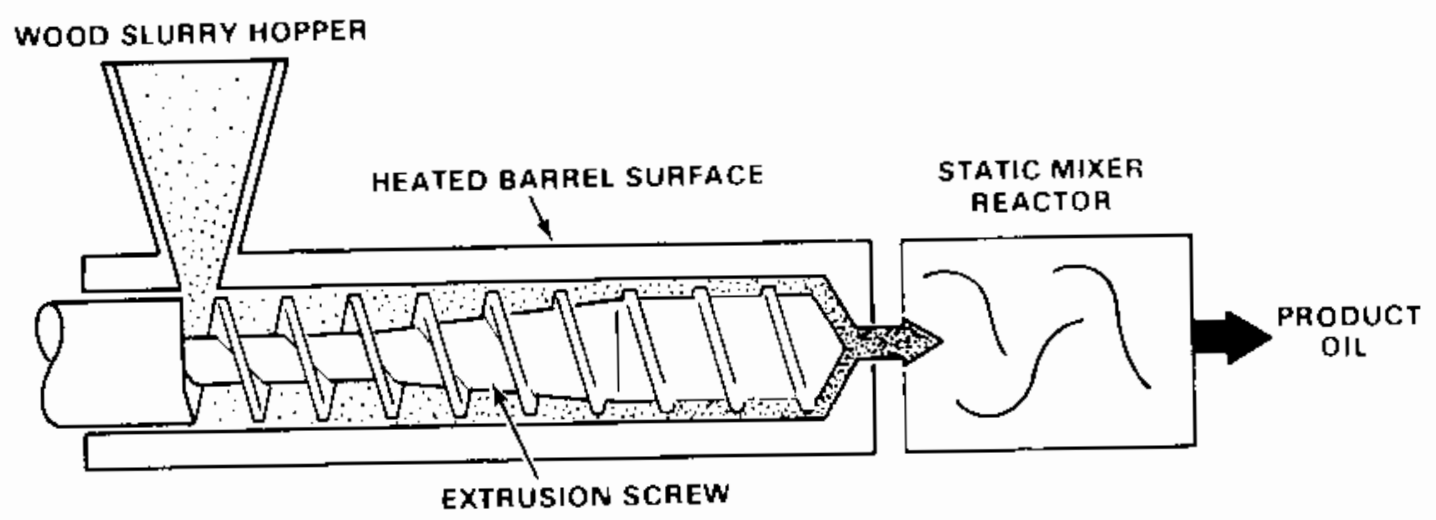

FIGURE 21. University of Arizona Extruder/Static Mixer Direct Liquefaction Reactor

PACIFIC NORTHWEST LABORATORY, Richland, washington, is conducting research on the characterization and upgrading of direct liquefaction oils. Characterization studies show that there are significant differences between the pyrolysis and the direct liquefaction oils. As shown in Table 1, pyrolysis oils contain more oxygen and are less viscous than the liquefaction products. The liquefaction products contain large quantities of phenolic compounds while the pyrolysis oils have large concentrations of organic acids. These differences directly impact the methods for upgrading these products. During 1983, the direct liquefaction 0 ils were successfuliy hydrotreated to form gasoline substitutes. Distillate fractions comprising the lighter half of the whole oil were successfully hydrotreated using cobalt-molybdenum catalysts. The hydrogenation is performed selectively to retain much of the aromatic nature of the biomass feedstock while simultaneousiy eliminating oxygen. The selective hydrogenation not only retains these high-value octane enhancing components but also uses less hydrogen than conventional, exhaustive hydrotreating concepts.

\section{DIRECT COMBUSTION TECHNOLOGY}

Direct combustion of biomass feedstocks, particularly wood, is already widely practiced by the private sector, especialiy in the forest products 
TABLE 1. Biomass Liquefaction Products

Comparative Analytical Data

\begin{tabular}{|c|c|c|}
\hline Elemental Analysis (MAF) & $\begin{array}{l}\text { Direct Liquefaction Dil } \\
\text { (PERC-Albany TR12) }\end{array}$ & $\begin{array}{l}\text { Fast Pyrolys is } 0 i 7 \\
\text { (Georgia Tech } \# 11 \text { ) }\end{array}$ \\
\hline Carbon & $81.0 \%$ & $59.2^{\alpha}$ \\
\hline Hydrogen & $10.2 \%$ & $7.0 \%$ \\
\hline Oxygen & $8.8 \%$ & $33.8 \%$ \\
\hline Nitrogen & $0.1 \%$ & $0.1 \%$ \\
\hline Sulfur & 1.50 & 1.41 \\
\hline \multicolumn{3}{|l|}{ Moisture and Heating Value } \\
\hline$\% \mathrm{H}_{2} \mathrm{O}$ & 7.3 & 19.7 \\
\hline raw HHV & $14,2008 \mathrm{tu} / 7 \mathrm{~b}$ & $7,950 \mathrm{Btu} / 1 \mathrm{~b}$ \\
\hline MAF HHV & $15,300 \mathrm{Btu} / 1 \mathrm{~b}$ & $9,800 \mathrm{Btu} / \mathrm{tt}$ \\
\hline \multicolumn{3}{|l|}{ Other Properties } \\
\hline viscosity cps $040^{\circ} \mathrm{C}$ & 400,000 & 62 \\
\hline density $g / \mathrm{mil}_{1} 023^{\circ} \mathrm{C}$ & 1.14 & 1.24 \\
\hline pourpoint & $27^{\circ} \mathrm{C}$ & $-15^{\circ} \mathrm{C}$ \\
\hline
\end{tabular}

industry. Prior to the introduction of extensive natural gas distribution systemis and cheap imported crude oil following World War II, many forest products companies utilized wood wastes from their operations to supply a large portion of their energy needs. In the current era of uncertain energy costs, there is widespread interest in returning to self-sufficiency in fuel supplies. Many types of direct combustion equipment, such as wood-fired boilers and various types of burners, are commercially available for this purpose.

Therefore, direct combustion projects funded by the Biomass Thermochemical Conversion Program have focused on unique, innovative combustion systems or special issues involved in combusting biomass fuels.

The Biomass Thermochemical Conversion Program is currently sponsoririg direct combustion research that is focused on determining the technical feasibility of converting the heat released from direct combustion directly 
into mechanical power. By directly producing mechanical power without the use of an intermediate working fluid such as steam in a boiler/steam turbine systeril, high conversion efficiencies can be realized. In addition, costs associated with the working fluid, such as boilers and condensers, are eliminated, allowing small engines to operate economically. The Biomass Thermochemical Conversion Program is also sponsoring research on the fundamental aspects of biomass combustion. This research is aimed at increasing our understanding of basic combustion rates and mechanisms, to both improve combustion efficiencies and lower undesired combustion emissions. As shown in Figure 22, the Program sponsored three biomass direct combustion projects during 1983.

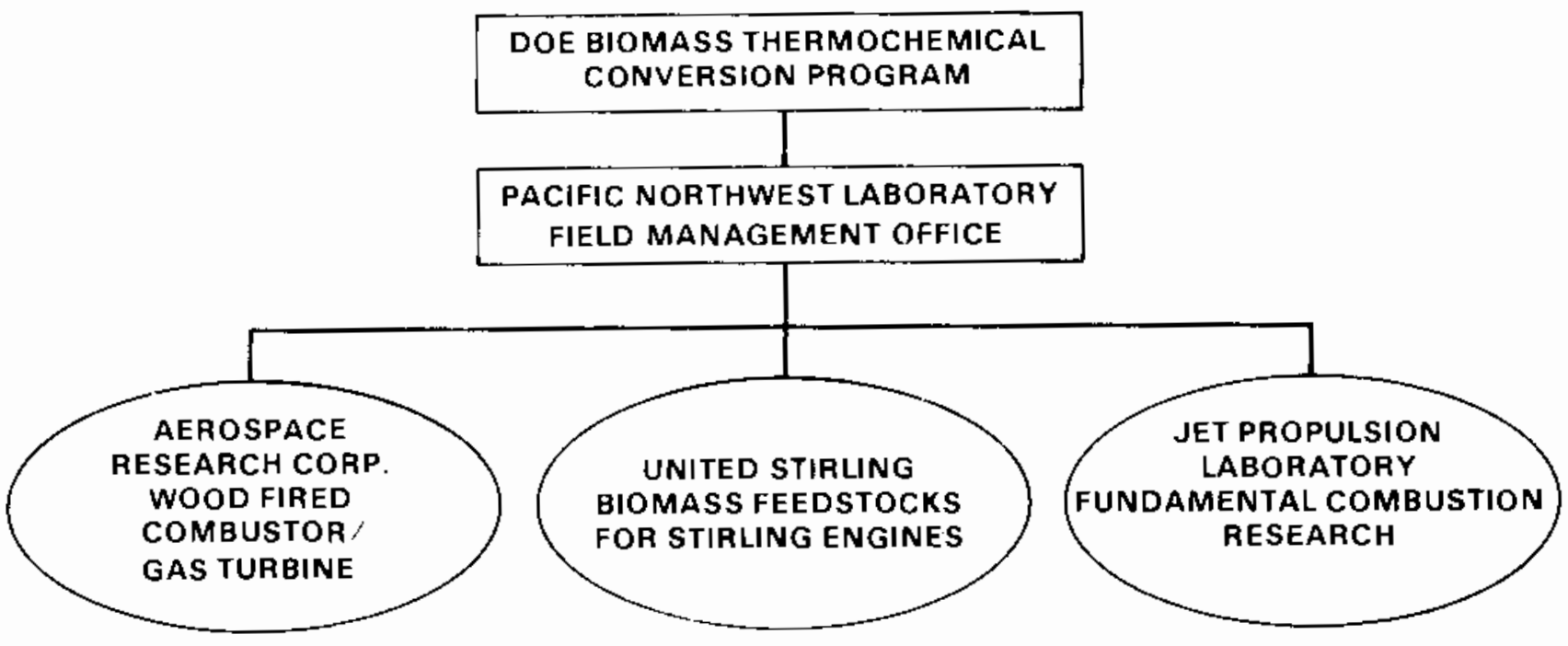

FIGURE 22. Direct Combustion Research Projects

AEROSPACE RESEARCH CORPORATION, Roanoke, Virginia, is conducting research on a directly-fired gas turbine generating system using wood feedstock. The objective of this project is to determine whether combustion gases from wood can be sufficieritly cleaned using a series of cyciones to power gas turbines dependably and economically. Hot combustion gases from a pressurized wood-fired suspension burner are passed through a series of cyclones to remove particulate matter and are injected directly into a gas turbirie. A schematic diagram of this concept is shown in Figure 23. Luring 1983, trials using a $375-\mathrm{kW}$ combustor/gas turbine were completed. After over 500 hours of operation, no significant signs of erosion or corrosion were evident. Tests 
showed that $80 \%$ to $90 \%$ of the particulates entering the gas turbine were less then 0.5 micron in diameter. Total particulate loading entering the turbine ranged from 0.0038 to 0.0056 grains per dry standard cubic foot of combustion gas. These results strongly suggest that turbine erosion will not be a problem.

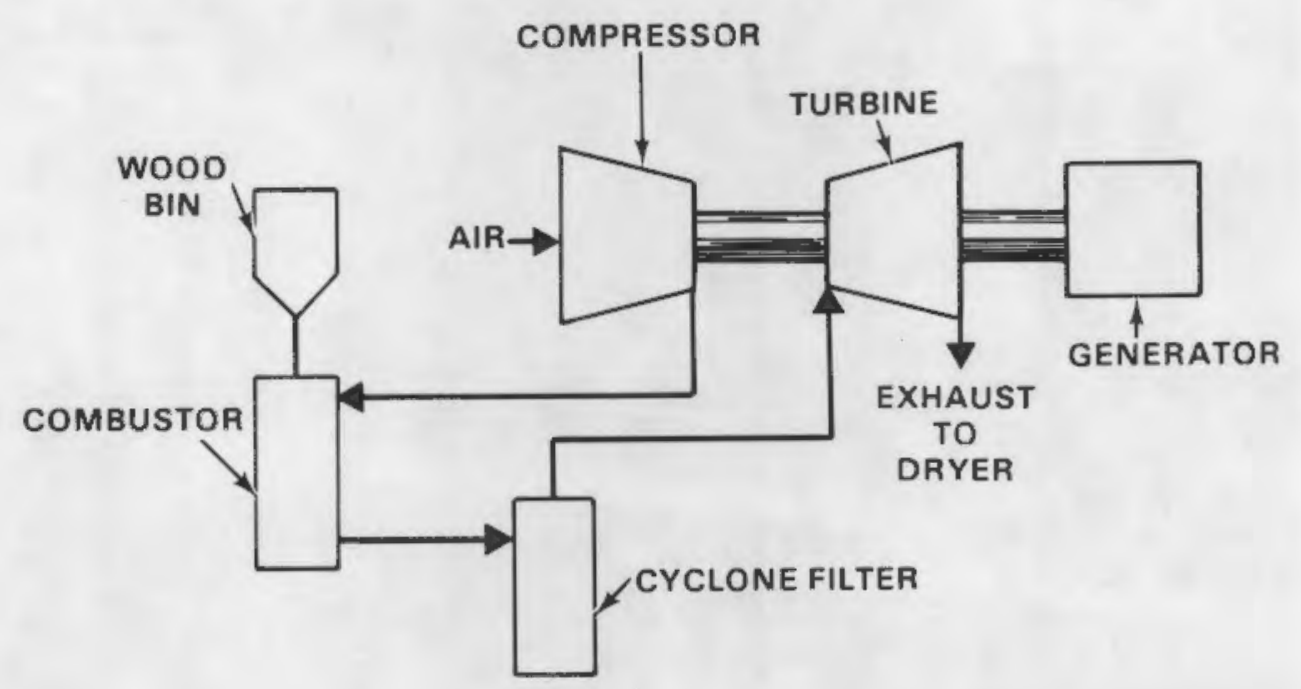

FIGURE 23. Combustor/Gas Turbine System at Aerospace Research Corporation

A 3000-kW combustor/gas turbine electrical generating system is currently under construction. After initial shakedown, the unit will be transported to Red Boiling Springs, Tennessee, where it will undergo long-term testing while generating electrical power to be sold to the Tennessee Valley Authority. Over $80 \%$ of the funds for the $3000-\mathrm{kW}$ unit are being provided by the private sector. The Allison Division of General Motors is donating the gas turbine for the project. The newly constructed cyclones for the $3000-\mathrm{kW}$ system are shown in Figure 24, and the turbine/generator set is shown in Figure 25.

UNITED STIRLING INCORPORATED, Alexandria, Virginia, completed research on the feasibility of using biomass to fuel Stirling engines. The external combustion feature and high efficiency make the Stirling engine an attractive candidate for the direct production of shaft horsepower from solid fuels such as biomass. Other DOE programs have already committed extensive resources to 


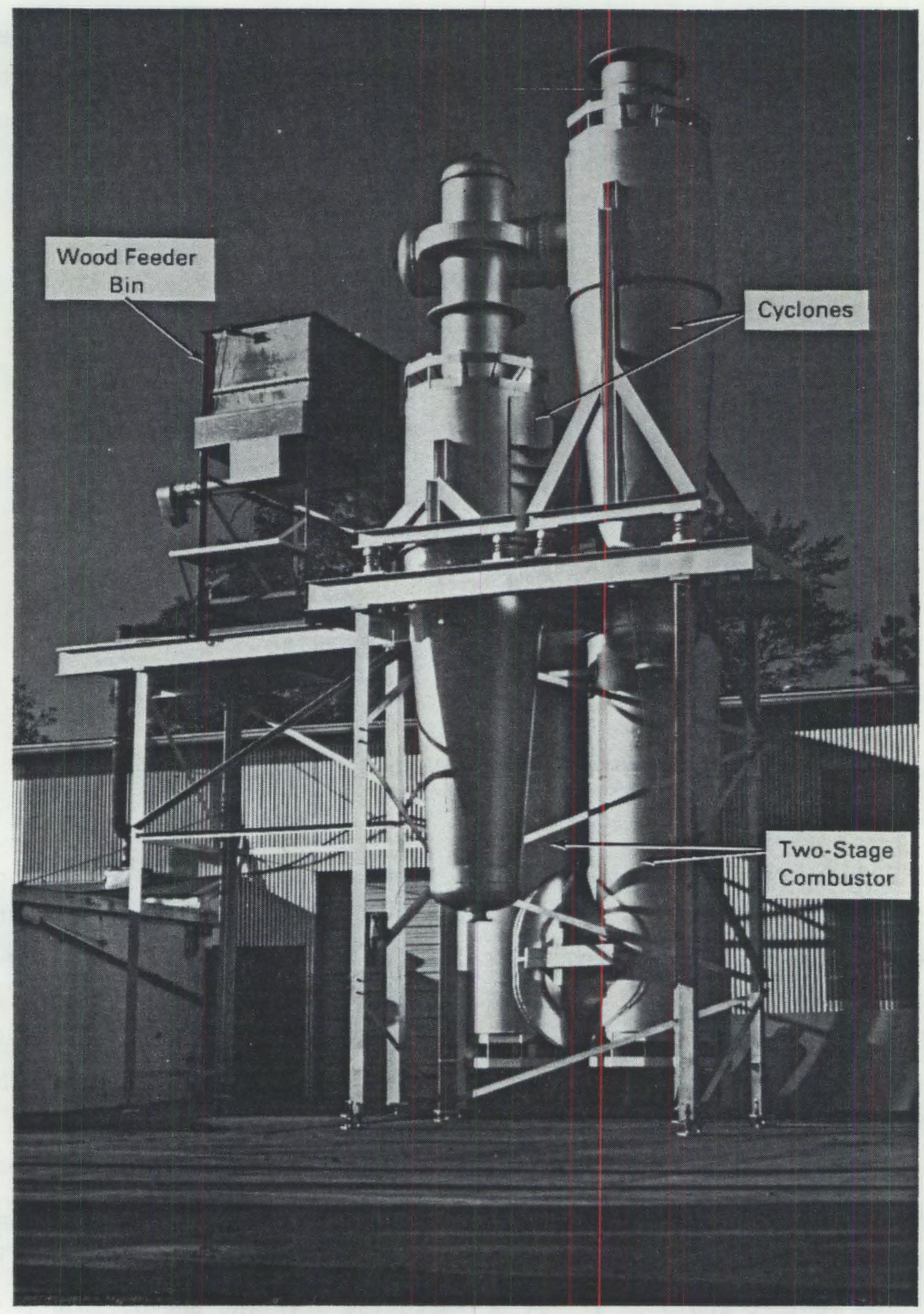

FIGURE 24. Two-Stage Combustor and Cyclones for 3-MW Combustor/Gas Turbine System at Aerospace Research Corporation 


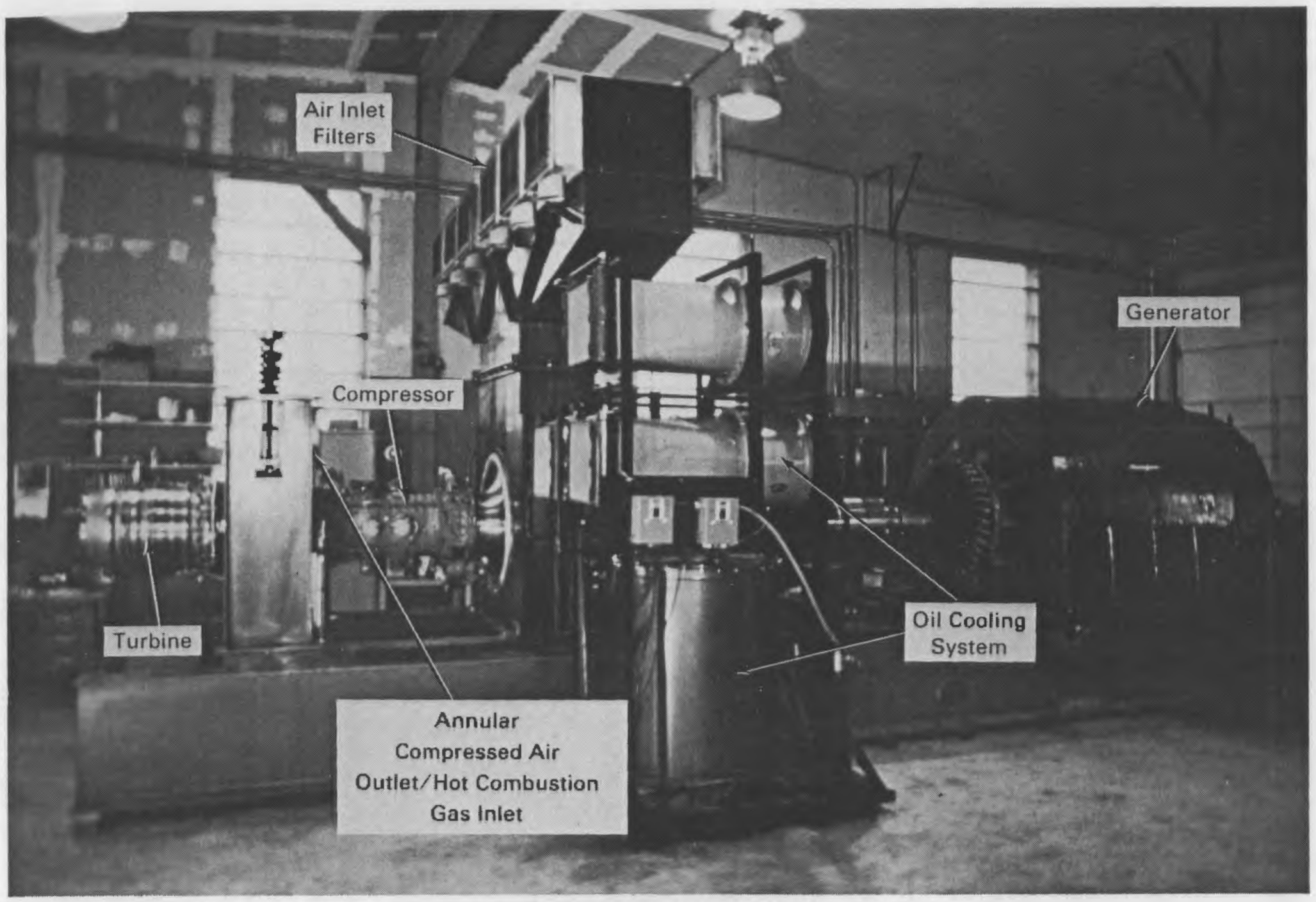

FIGURE 25. 3-MW Gas Turbine and Generator Set at Aerospace Research Corporation 
the development of improved Stirling engines. The scope of this project was limited to the adaptation of Stirling engines to biomass fuels.

The main emphasis of this research has been to provide heat to the heat exchanger of the Stirling engine. Based on experimental data obtained in 1982, a two-stage cyclonic combustor was chosen as the most feasible method for providing the heat input. The first stage acts as an airblown gasifier in which hot combustible gases are generated and separated from the bulk of the ash. Combustion is completed in the second stage and the hot combustion gases are passed through the elaborate Stirling engine heat exchanger. The two-stage combustion approach minimizes ash fouling of the Stirling engine heat exchanger. The two-stage combustor was coupled with a United Stirling engine and extended tests were performed. The testing was successfully completed after 100 hours of operation, which showed the technical feasibility of this approach.

JET PROPULSION LABORATORY, Pasadena, California, began basic research on biomass combustion reactions. This work will develop a predictive model that correlates combustion behavior with wood particle size, type, moisture content, and heating value. Experimental verification of the predictive model will also be performed. In addition, the research will explore the effect of additives such as alkali salts on combustion behavior. The results of this research will be used to develop a more complete fundamental understanding of combustion reactions. By applying this knowledge, combustion processes that are both more complete and more environmentally acceptable should be possible.

PROGRAM SUPPORT ACTIVITIES

During 1983, the Biomass Thermochemical Conversion Program sponsored additional research activities with the goal of supporting major program elements. This research includes technoeconomic evaluation of candidate processes, evaluation of feedstock availability, examination of methods for reducing aqueous effluents in biomass gasification systems, and studies of using biomass/coal/MSW briquets in conversion systems. Program support research is shown in Figure 26. 


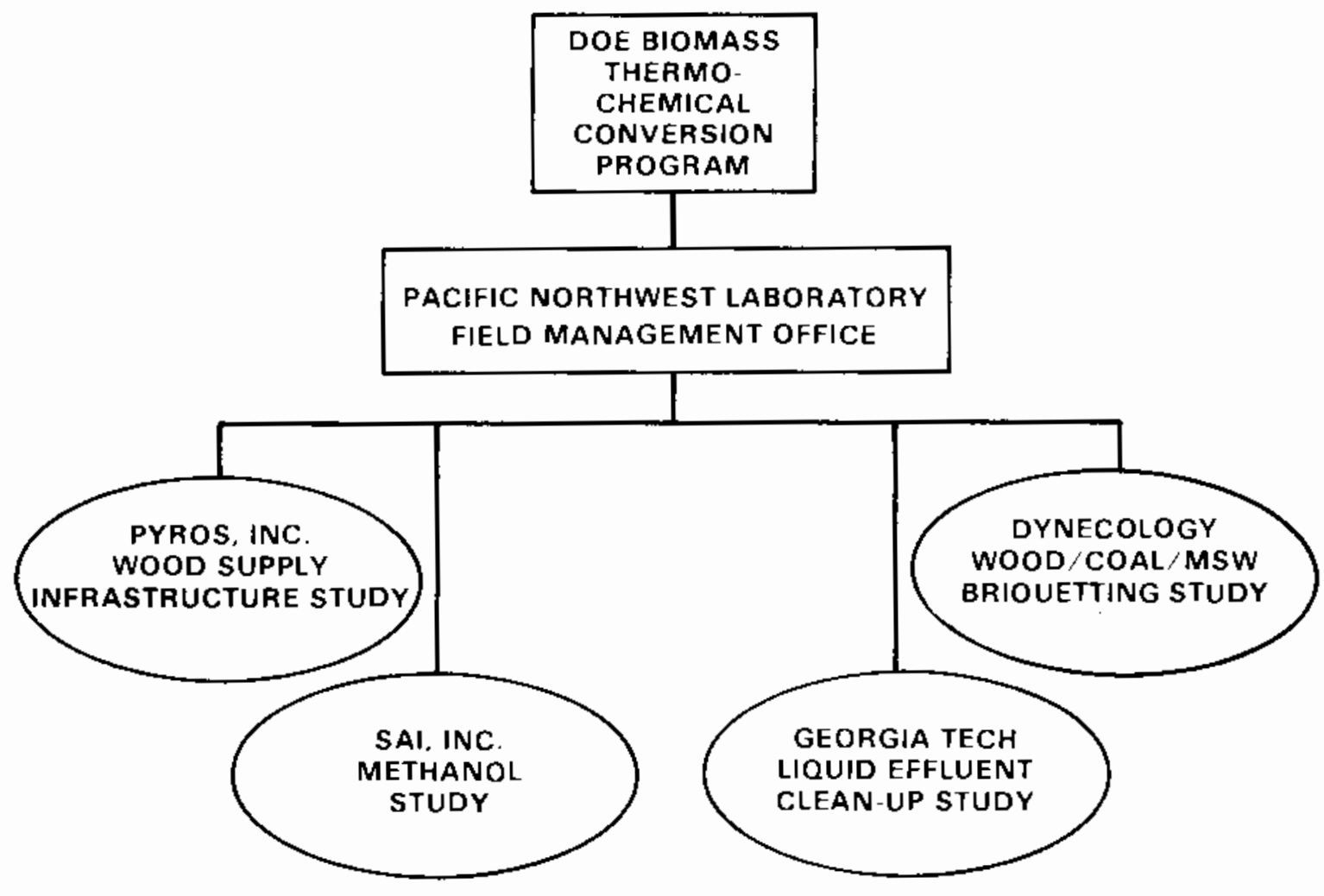

FIGURE 26. Program Support Research Projects

SCIENCE APPLICATIONS, INCORPORATED (SAI), Arlington, Virginia, conducted engineering and economic studies to assess advanced biomass conversion concepts. During 1983 SAI completed a biomass-to-methanol process sensitivity analysis to identify controllable process parameters that would affect overail methanol process efficiency. The analysis examined the effects of feedstock composition, gasification temperature, steam rate, optimal $\mathrm{H}_{2} / \mathrm{CO}$ ratio, pressure, and other factors. Overall efficiency was found to correlate directly with the carbon content, steam to wood ratios, and heating value of the feedstock. Lower steam rates and higher temperatures increase overall efficiency. At low steam rates, thermal efficiencies increase from 53\% to $57 \%$ as temperature increases from 700 to $900^{\circ} \mathrm{C}$. Maximum thermal efficiencies were reached with $\mathrm{H}_{2} / \mathrm{CO}$ ratios of 2.0 to 2.6 , depending on gasifier pressure. These results suggest that emerging gasification concepts carn be improved by optimizing these and other parameters. SAI, Inc., also completed a prelimi- 
nary analysis of an advanced flash pyrolysis process based on the research at Brookhaven National Laboratory. Although flash pyrolysis is still at an early research stage and major uncertainties exist, the analysis indicates that there may be considerable potential for the advanced pyrolysis coricept.

PYFOS, INCORPORATED, Gaithersburg, Maryland, completed a study to determine the potential for supplying wood feedstocks to intermediate-size (500 to 2000 tons/day of wood) conversion facilities in the northeastern and solitheastern United States. This study is based in part upon the experiences gained by the Burlingtor Electric Department in setting up a wood supply infrastructure for a 50-MW electric power plant in Vermont. The study concluded that there are substantial quantities of forest biomass in both the northeastern and southeastern U.S. However, some major differences in these potential supplies exist. In the Northeast, for example, the resource base is divided into many small parcels with many owners. The small parcels mariy be more difficult to econumicaliy harvest than the larger units in the southeastern U.S. These issues are not expected to be serious barriers to biomass utilization but should be considered in planning for adequate resources.

GEORGIA TECH, Atlanta, Georgia, is conducting research to reduce tar ana aqueous effluents in biomass gasification systenis. The concept uses an exterrial combustor to burn tars produced in an updraft gasifier. The hot combustion products will then be used to vaporize a portion of the aqueous effluent. The resulting mixture is used as a moderator gas in the gasifier, thus eliminating the need for a separate steam boiler. The concept also provides for destruction of the difficult-to-handle tars that otherwise would present disposal problems. During 1983, Georgia Tech designed and begari construction of a system coupled to their gasifier that will simulate the injection of the tar combustion products and steam into an updraft gasifier. A predictive model has also been developed; that will be used to estimate the effects of displacing part of the air flow through the gasifier with the moderator gas prociced in the combustor. The results are expected to provide important information for designing the tar combustor/waste water vaporizer system to be tested later in the program. 
OYNECOLOGY INCORPORATEO, New York, New York, is conducting research to determine the feasibility of using biomass/coal/sewage sludge briquets in gasification systems. The addition of biomass to the briquets reduces the caking tendencies of certain agglomerating coals. The effects of composition and compaction pressure on briquet strength are being measured. Compaction pressures of 10,000 psi resulted in briquets that were $38 \%$ stronger than those produced at 5,000 psi. However, those produced at 15,000 psi were on ly $42 \%$ stronger than the 5,000-psi briquets. This indicates that additional compaction beyond $10,000 \mathrm{psi}$ is unnecessary. Results to date also indicate that the sewage sludge in the composite briquets is quite stable to biological growth and that lime stabilizer can be minimized. The data will be used to form optimal briquets for extended gasification tests.

\section{Additiona] Information}

Detailed descriptions of all the research and development projects funded by the Biomass Thermochenical Conversion Program are given in the Proceedings of the 15th Biomass Thermochemical Conversion Contractors' Meeting, June 1983. This document, CONF-830323, is available from the National Technical Information Service, United States Department of Commerce, 5285 Port Royal Road, Spririgfield, Virginia 22161. Additional information is also available from the publications Tisted in the Appendix. 

APPENDIX

BIOMASS THERMOCHEMICAL CONVERSION PROGRAM 


\section{PROGRAM MANAGEMENT}

Project TitTe: Bjomass Thermochemical Conversion Program Management - Lead Laboratory - Pacific Northwest Laboratory

Proceedings of the 15 th Biomass Thermochemical Conversion Contractors Meeting, March 16-17, 1983. Atlanta, Georgia. CoNF-830323, National Technical Information Service, Springfield, Virginia.

Schiefelbein, G. F. 1983. "Overview of DOE's Biomass Thermochemical Conversion Program." Paper presented at the Industrial Wood Energy Forum ' 83 , September 19-21, 1983, Nashville, Tennessee. Proceedings to be published by Forest Products Research Society, Madison, Wisconsin.

Stevens, 0. J. 1983. "Liquid Fuels from Biomass: An Overview of Research Activities Funded by DOE's Thermochemical Conversion Program." Paper presented at the Industrial Wood Energy Forum '83, September 19-21, 1983, Nashville, Tennessee. Proceedings to be published by Forest Products Research Society, Madison, Wisconsin.

Gerber, M. A. 1983. "Overview of the U.S. Department of Energy's Biomass Thermochemical Conversion Program." In Proceedings of the Southern Biomass Energy Research Conference, Tuscalcosa, Alabama.

Stevens, D. J., and G. F. Schiefelbein. 1983. "Overview of Biomass Liquefaction Activities Sponsored by the U.S. Department of Energy." In Proceedings of the 33rd Caradian Chemical Engineering Society Meeting, Toronto, Ontario.

Stevens, D. J. 1983. "Overview of Biomass Thermochemical Conversion Research Sponsored by the U.S. Department of Energy. "S Paper presented at the Rocky Mountain Fuel Society, February 24-26, 1983, Salt Lake City, Utah.

Schiefelbein, G. F., D. J. Stevens and M. A. Gerber. 1983, 1982 Annual Report: Biomass Thermochemical Conversion Program. PNL $-47 \overline{79}$, Pacific Northwest Laboratory, Richland, Washington. 
GASIFICATION TECHNOLOGY

Project Title: Development of Biomass Gasification to Produce Substitute Fuels - Institute of Gas Technology

Kosowski, G. M., M. Onischak, and S. P. Babu. 1983. "Development of Biomass Gasification to Produce Substitute Fuels." In Proceedings of the 15th Biomass Thermochemical Conversion Contractors' Meeting. CoNf-830323, National Technical Information Service, Springfield, Virginia.

Onischak, M., S. P. Babu, and G. M. Kosowski. 1983. "Support Research for Biomass Thermal Gasification Development." Paper presented at the International Gas Research Conference, June 13-16, 1983, London, England.

Project Title: Conversion of Forest Residues to a Methane-Rich Gas Battelle-Columbus Laboratories

Appelbaum, H. R., M. A. Paisley, and H. F. Feldmann. 1983. "The Technology and Economics of Medium-Btu Gas From Biomass in a High-Throughput Gasifier." Paper presented at the Industrial Wood Energy Forum '83, September 19-21, 1983, Nashville, Tennessee.

Charig, H., R. C. Nieman, and Kenneth E. Wilzbach (Argonne National Laboratory) and M. A. Paisley (Battelle-Columbus Laboratories). 1983. "Environmental Characterization Studies of a High-Throughput Wood Gasifier." In Proceedings of Energy from Biomass \& Wastes VII, pp. 539-544. Institute of Gas Technology, Chicago, Illinois.

Feldmann, H. F., M. A. Paisley, and H. R. Appelbaum. 1983. "Industrial Co-Generation Through Use of a Medium Btu Gas from Biomass Produced in a High-Throughput Reactor." Paper presented at the Energy Technology Conference and Exhibition, American Society of Mechanical Engineers, January 30- February 3, 1983, Houston, Texas.

Feldmann, H. F., M. A. Paisley, and H. R. Appelbaum. 1983. "Gasification of Forest Residues in a High-Throughput Gasifier." In Proceedings of the 15th Biomass Thermochemical Conversion Contractors' Meeting. CONF-830323, National Technical Information Service, Springfield, Virginia.

Project Title: Investigation of Gasification of Bionass in the Presence of Catalysts - Pacific Northwest Laboratory

Baker, E. G., L. K. Mudge, and W. A. Wilcox. 1982. "Catalysts of Gas-Phase Reactions in Steam Gasification of Biomass." Paper presented at the International Conference on Fundamentals of Thermochemical Eiomass Conversion, October 18-22, 1983, Estes Park, Colorado. 
Baker, E. G., L. K. Mudge, and D. H. Mitchel1. 1984. "Oxygen/Steam Gasification of Wood in a Fixed-Bed Gasifier." Industrial \& Engineering Chemistry Process Design and DeveTopment. 23(4).

Baker, E. G., D. H. Mitchell, L. K. Mudge, and M. D. Brown. 1983. "Catalytic Steam Gasification of Wood for the Production of Methanol Synthes is Gas." Paper presented at the AICHE National Meeting, March 27-31, 1983, Houston, Texas.

Brown, M. D. and D. H. Mitchel1. Forthcoming. "Hot Gas Equilibrium." Chemical Engineering.

Brown, H. D., D. H. Mitche11, L. K. Mudge, R. J. Robertus, and E. G. Baker. 1983. "Methanol Production by Catalytic Gasification of Wood." ASME paper \#83-PET-33. Paper presented at the Second Synthetic Fuels Symposium, February 1983, Houston, Texas.

Muóge, L. K., E. G. Baker, D. H. Mitchell, M. D. Brown, and R. J. Robertus. 1983. "Catalytic Steam Gasification of Biomass for liethanol and Methane Production." In Proceedings of Energy From Bionass and Wastes VII, pp. 365-411. Institute of Gas Technology, Chicago, Illinois.

Mudge, L. K., E. G. Baker, R. J. Robertus, ard M. D. Brown. 1983. "Progress in Studies on Catalyzed Gasification of Wood." In Proceedings of the 15th Biomass Thermochemical Contractors Meeting. CoNF-830323, National Technica Information Service, Springfield, Virginia.

Project Title: Steam Gasifjcation of Wood in a Fluidized Bed Using Fire Tubes to Provide Reactor Heating - University of Missouri-Rolla

Flanigan, V. J., M. E. Findley, and H. Sineath. 1983. "Steam Gasification of Wood in a Fluidized Bed Using Indirect Heating Fire Tubes." In Proceedings of the 15th Biomass Thermochemical Conversion Contractors' Meeting, CONF-830323, National Technical Information Service, Springfield, virgiria.

Flanigan, V. J., arıd J. Chereau. 1983. "Effect of Operating Conditions on Gas Quality and Conversion Efficiency of a Fluidized-Bed Gasifier for Wood, Manure, aric Peat." In Proceedings of Energy from Biomass and Wastes VII. Institute of Gas TechnoTogy, Chicago, IT1inois.

Flanigan, V. J., M. E. Findley, and J. Cherian. 1983. "Fluidized Bed Gasification of Lignite, Peat, and Biomass." Paper presented at the American Society of Civil Engineers' Fall Converition and Structures

Congress, New Orleans, Louisiana.

Flanigan, V. U., and W. O'Neill. 1983. "Small Fluidized Gasifier Using Charred Biomass." In Proceedings of International Producer Gas Conference, The Beijer Institute, Stockholm, Sweder. 
Flanigan, V. J., and C. O'Reility. 1983. "An Internally Heated Steam Fluidized Bed Wood Gasifier." Paper presented at the Energy Technology Conference \& Exhibition. 83-Pet-32, American Society of Mechanical Engineers, January 30 - February 3, 1983, Houston, Texas.

Lin, T. J. "Fixed Bed Wood Gasification with Recirculation." Master's Thesis, University of Missouri-Rolla, Rolla, Missouri.

0'Neill, W. 1983. "4" Fluidized Bed Char Gasifier." Master's Thesis, University of Missouri, Rolla, Missouri.

0'Reilly, C. 1983. "An Internally Heated Steam Fluidized-Bed Wood Gasifier." Master's Thesis, University of Missouri, Rolla, Missouri.

Project Title: Development of an Indirectly Heated Radiant Reactor for Bioniess - Texas Tech University

Clements, L. D., C. H. Cho, R. Moser, H. Y. Fang, L. L. Ginn, and J. P. Jeffrey. 1983. "Developmient of an Indirectly Heated Pyrolys is Reactor." In Proceedings of 15th Biomass Thermochemical Conversion Contractors' Meeting. National Technical Information Service, Springfield, Virginia. 


\section{LIQUID FUELS TECHNOLOGY}

Project Title: Flash Pyrolysis of Biomass - Brookhaven National Laboratory

Steinberg, M., P. T. Fallon, and M. S. Sundaram. 1983. "The Flash Pethanolysis of Wood for the Production of Fuels and Chemicals." In Proceedings of the IGT Conference on Biomass Conversion. BNL 32400-R, Brookhaven National Laboratory, Long Island, New York.

Steinberg, M., P. T. Fallon, and M. S. Sundaram. 1983. "Flash Pyrolysis of Biomass with Reactive and Non-Reactive Gases." Proceedings of the 15th Biomass Thermochemical Conversion Contractors' Meeting. CONF-830323, National Technical Information Service, Springfield, Virginia.

Sundaram, M. S., M. Steinberg, and P. T. Fallon. 1982. "Flash Pyrolysis of Biomass with Reactive and Non-Reactive Gases." Paper presented a $\tau$ the International Conference on the Fundamentals of Thermochemical Eiomass Conversion, October 18-20, 1982, Estes Park, Colorado. BNL 32280, Brookhaven National Laboratory, Long Is Iand, New York.

Sundaram, M. S., M. Steinberg, and P. T. Fallon. 1983. "Flash Pyrolysis Process for the Production of Chemicals and Fuels from Biomass." Paper presented at the 185th ACS National Meeting, March 20-25, 1983, Seattle, Washington. BNL 32729, Brookhaven National Laboratory, Long Island, New York.

Project Title: Furidamental Pyrolysis Studies - Solar Energy Research Institute

Milne, T. A., and M. N. Soltys. 1983. "Direct Mass-Spectrometric Studies of the Pyrolysis of Carbonaceous Fuels. 1. A Flame-Pyrolysis, MolecularBeam Sampling Technique." J.Anal. Appl. Pyrol. 5: 93-110.

Milne, T. A., and M. N. Soltys. 1983. "Direct Mass-Spectrometric Studies of the Pyrolysis of Carbonaceous Fuels. II. Qualitative Observations of Prinary and Secondary Processes in Biomass." J.Aral. Appl. Pyrol. 5: $111-131$.

Milne, T. A., M. N. Soltys, and R. J. Evans. 1983. "Fundamental Pyrolysis Studies." In Proceedings of the 15th Biomass Thermochemical Conversion Contractors' Meeting, CONF-830323, National Technical Information Service, Springfield, Virginia.

Milne, T. A., M. N. Soltys, and R. J. Evans. 1983. "Direct Molecular-Beari Mass Spectrometric Study of the Primary and Secondary Pyrolysis of Carbonaceous Materials." Poster presented at the Gordon Conference on Analytical Pyrolysis, July 11-15, 1983, Plymouth, New Hampshire. 
Milne, T. A., and R. J. Evans. 1983. "Carbohydrate Pyrolysis." Paper presented at the Gordon Conference on Analytical Pyrolysis, July 11-15, 1983, Plymouth, New Hampshire.

Milne, T. A. and M. N. Soltys. 1983. "The Direct, Mass-Spectrometric Study of the Primary and Secondary Pyrolysis Behavior of Biomass and Its Constituents." Paper presented at the International Conference on Fundamentals of Thermochemical Biomass Conversion, October 18-22, 1983, Estes Park, Colorado.

Project Title: Entrained Flow, Ablative Fast Pyrolysis of Biomass Solar Energy Research Institute

Diebold, J., and J. Scahill. 1983. "Ablative Entrained-Flow Fast Pyrolysis Status." In Proceedings of the 15th Biomass Thernochemical Conversion Contractors' Meeting. CoNF-830323, National Technical Information Service, Springfield, Virginia.

Diebold, J. 1983. "Chemical Feedstocks." Paper presented at the Gordon Conference on Analytical Pyrolysis, July 11-15, 1983, Plymouth, New Hampshire.

Viebold, J. and J. Scahill. 1983. "Ablative Pyrolysis in Solid Convective Heat Transfer Environments." Paper presented at the International Conference on Fundamentals of The mochemical Biomass Conversion, October 18-22, 1983, Estes Park, Colorado.

Project Title: Research on the Pyrolysis of wood to Produce Liquid Fuels Georgia Tech

Knight, J. A., C. W. Gorton, and R. J. Kovac. 198j. "Entrained Flow Pyrolys is of Biomass." In Proceedings of the 15th Biomass Thermochenicai Conversion Contractors' Meeting. CoNF-830323, National Technical Information Service, Springfield, Virginia.

Knight, J. A., C. W. Gorton, arid K. J. Kovac. 1983. "0i] Production by Entrained Flow Pyrolysis of Biomass." Paper presented at Industrial Wood Energy Forum '83, September 20, 1983, Nashville, Tennessee.

Knight, J. A. and C. W. Gorton. 1983. "0il Production by Entrained Flow Pyrolysis of Biomass." Paper presented at Third Canadian Biomass Liquefaction Experts Meeting, 1983, University of Sherbrook, Quebec, Canada. 
Project Title: Characterization and Upgrading of Biomass Pyrolysis and Liquefaction Projects - Pacific Northwest Laboratury

Elliott, D. C. In press. "Analysis and Comparison of Products from wood Liquefaction." Paper preserted at the International Conference on Fundamentals of Thermochemical Biomass Conversion, October 18-22, 1983, Estes Park, Colorado.

Elliott, D. C. 1983. "Hydrodeoxygenation of Phenolic Components of Wood-Derived 0i1." American Chemical Society, Div. Petr. Chem. Prepts. 28(3): $667-674$.

Elliott, D. C. 1983. "Basic Research in Biomass Direct Liquefaction." In Proceedings of the 15 th Biomass Thermochemical Conversion Contractors Meeting. CoNF-330323, National Technical Information Service, Springfield, Virginia.

Schimier, R. E., T. R. Pahl, and D. C. Elliott. Forthcoming. "Analysis of a Thermochemically Derived Wood 0il." FUEL.

Project Title: Advanced Laboratory Scale Extruder - Reactor Biomass Liquefaction Unit - Unjversity of Arizona

White, D. H. 1983. "Advanced Laboratory-Scale Extruder Reactor Biomass Liquefaction Unit." In Proceedings of the 15th Biomass Thermochenical Conversion Contractors Meeting. CoNF-830323, National Techrical Information Service, Springfield, Virginia. 


\section{DIRECT COMBUSTION}

Project Tit?e: Development of Wood as an Alternative Fuel for Gas Turbine Systems - Aerospace Research Corporation

Hamrick, J. T. 1983. "Development of Wood as an Alternative Fuel for Gas Turbine Systems." In Proceedings of the 15th 8 iomass Thermochemical Conversion Contractors Meeting. CoNF-830323, National Technical Information Technical Service, Springfield, Virginia.

Hanirick, J. T. 1983. "Research on a Wood Burning Gas Turbine." Paper presented at the 15th International Congress on Combustion Engines, June 14, 1983, Paris, France.

Hamirick, J. T. 1983. "Wood Burning Gas Turbine Gen Set." Paper presented at the Industrial Wood Energy Forum ' 83 , September 20, 1983, Nashville, Tennessee.

Project Title: Biomass Fueled Stirling Engine System Research - United Stirling

Percival, W. H., S. Gummesson, and B. Hansson. 1983. "Biomass Fueled Stirling Engine Combustor Research." In Proceedings of the 15th Biomass Thermochemical Conversion Contractors' Meeting. CONF-830323, Nationat Technical Information Service, Springfield, Virginia. 
PROGRAM SUPPORT RESEARCH

Project Title: Technical and Economic Assessment of Emerging Biomass Thermochemical Conversion Technologies - Science Applications, Incorporated

War, E. I., and J. D. Price. 1983. Technical and Economic Assessnient of Liquid Fuel Production fromi Biomass, Final Research Report. DOE/NBM 1061, National Technical Information Service, Springfield, Virginia.

Wan, E. I. and J. D. Price. 1983. "Technical and Economic Assessment of Enterging Advanced Biomass Thermochemical Conversion Techniques." In Proceedings of the 15th Biomass Thermochemical Conversion Contractors' Meeting. CONF-830323, National Technical Iriformation Service, Springfield, Virginia.

Project Title: Assessment of Potential Wood Supply for Intermediate Scale Thermoconversion Facilities - Pyros, Incorporated

Orr, F. E. 1983. "Assessment of Potential Wood Supply for Intermediate Scale Thermoconversion Facilities." In Proceedings of the 15th Biomass Thermochemical Conversion Contractors' Meeting. CONF-830323, National Technical Information Service, Springfield, Virginia.

Project Title: Gasifier Tar Effluerit Disposal - Georgia Tech

McGowan, T. F., A. D. Jape, and J. L. Walsh. 1983. "Utilization of Waste Streans in Biomass Gasifiers." In Proceedings of the 15th Biomass Thermochemical Conversion Contractors Meeting. CONF-830323, Nationa 1 Technical Information Service, Springfield, Virginia.

Project Title: liethods for Producing Clean Eriergy from Forest Pulp, Coal, and Sewage - Oynecology, Incorporated

Schulz, R. B., and S. K. Kenda. 1983. "The Simplex Coal and Biomass Gasification Process." Paper presented at the Coal Technology 1982 Conference, December $7-9$, 1982, Houston, Texas. 


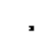

. 
PNL -5096

UC $-61 a$

\section{DISTRIBUTION}

No. of

Copies

OFFSITE

Beverly Berger, Director

Bionass Energy Technology Division

L.S. Department of Energy

Forrestal Building (CE-321)

1000 Independence Avenue

Washington, D.C. 20585

20 Simon Friedrich

Biomass Energy Technology Division

U.S. Department of Energy

Forrestal Building (CE-321)

1000 Independence Avenue

Washington, D.C. 20585

Phil Adamsak

Bioenergy Bulletin

Bonneville Power Administration

U.S. Department of Energy

2075 S.W. 78th Avenue

Portland, OR 97225

Jerome F. Collins, Chief

Alternative Materials Util. Br.

Office of Industrial Programs

U.S. Department of Energy

1000 Independence Avenue, SW

Washington, D.C. 20585

Patrick Fox

Biomass Program Manager

Bonneville Power Administration

Routing, EPG

U.S. Department of Energy

P.0. Box 3261

Portland, $O R \quad 97208$

Sig Gronich

Office of Alcohol Fuels

U.S. Department of Energy

Forrestal Building, (CE-80)

Washington, D.C. 20585
No. of

Copies

Martin Gutstein

Biomass Energy Technology Division

U.S. Department of Energy

Forrestal Building (CE-321)

1000 Independence Avenue

Washington, D.C. 20585

J. Peter Holihau

Biomass Energy Technology Division

U.S. Department of Energy

Forrestal Euilding (CE-321)

1000 Independence Avenue

Washington, D.C. 20585

W. Nelson Lingle

Oak Ridge Operation Office

U.S. Department of Energy

P.0. Box E

Oak Ridge, TN 37830

Walt Myers

Bonneville Fower Administration

U.S. Department of Energy

Mail Stop EP

P.0. Box 3621

Portland, OR 97208

Russ 0'Conne]1

Biomass Energy Technology

Division

U.S. Department of Eriergy

Forrestal Building (CE-321)

1000 Independence Avenue

Washington, D.C. 20585

Richard Orrison

Biomass Energy Technology Division

U.S. Department of Energy

Forrestai Building (CE-321)

1000 Independence Avenue

Washington, D.C. 20585 
No. of

Copies

\author{
Pat Pickering \\ Biomass Energy Technology Division \\ U.S. Department of Energy \\ Forrestal Building (CE-321) \\ 1000 Independence Avenue \\ Washington, D.C. 20585 \\ Delores Pollard \\ Biomass Energy Technology Division \\ U.S. Department of Energy \\ Forrestal Building (CE-321) \\ 1000 Independence Avenue \\ Washington, D.C. 20585 \\ Robert Rosenthal \\ ER-32 \\ U.S. Departinent of Energy \\ A14024GTN \\ Washington, D.C. 20545 \\ Douglas B. Seely \\ Bonneville Power Administration \\ U.S. Department of Energy \\ 1002 N.E. Holladay Street \\ P.0. Box 3621 \\ Portiand, OR 97208 \\ Donald $k$. Walter \\ Office of Energy from \\ Municipal Waste \\ CE-323 Forrestal Building \\ U.S. Department of Energy \\ 1000 Independence Avenue, SW \\ kashington, D.C. 20585 \\ Beverly Yocuni \\ Biomass Energy Technotogy Division \\ U.S. Department of Energy \\ Forrestal Building (CE-321) \\ 1000 Independence Avenue \\ Washington, D.C. 20585 \\ 27 DOE Technical Information \\ Center
}

No. of

Copies

John Allen

Battelle-Columbus Laboratories

505 King Avenue

Columbus, $\mathrm{OH} 43201$

Michael J. Antal, Jr.

Coral Professor

Dept. of Mechanical

Engineering

University of Hawai

2540 Dole Street

Honolulu, HI 9682 c

John C. Arbo

Dynecology Incorporated

611 Harrison Avenue

New York, NY 10528

Joseph A. Asbury

Energy \& Environmental Systems Division

Argonne National Laboratory

9700 South Cass Ave.

Argonne, IL 60439

Wi 11 iam (Bi11) Ayres

Buck Rogers Co., Inc.

150 Industrial Parkway

Industrial Airport, KS 66031

Suresh Babu

Institute of Gas Technology

IIT Center

3424 South State Street

Chicago, IL 60616

W. G. Bair

Assistant Vice Presjdent

Process Research

Institute of Gas Technology

3424 South State Street

Chicago, IL 60616 
Ho. of

Copies

Andrew J. Baker

Chenistry \& Paper Research

U.S. Forest Products Lab

P.0. Box 5130

Madison, WI 53705

David Bancroft

Council of Great Lakes Governors

122 West Washington Ave., \#801A

Madison, WI 53703

Peter Bensor

Gas Research Institute

8600 West Bryn Mawr Avenue

Chicago, IL 60613

Paul F. Bente, Jr.

The Bio-Energy Courici] 825A

1625 Eye St., NW

washington, D.C. 20006

Walter L. Berry, ur.

Rust Engineering Company

P.0. Box 101

Birminghals, AL 35201

Desmond $H$. Bond

Energy \& Env. Eng. \& Eco. Migt.

Desmond Bond, Inc.

2416 Luckett Avenue

Vienna, VA 22180

Eric F. Brandt

Vice President, Operations

Baryan Technology Corporation

7515 Greenville Avenue, Suite 711

Dallas, TX 75231

Buford Brauniger

12978 Bellevue Est's Drive

Creve Coeur, MC 63141

Oona 1d L. Brelsfurd, President

Renewable Energy Systems Enyineers

Brelsford Engineering, Inc.

P.0. Box 1252

Bozeman, MT 59715
No. of

Copies

Phillip Bridges

Conrad Industries

606 Reynolds Avenue

Centralia, WA 98531

Stanley Bull, Manager

Planning \& Evaluation Office

Solar Energy Research Institute 1617 Cole Slvd.

Golden, C0 80401

William S. Bulpitt, Chief Wood Energy Systems Division Engineering Experiment Station Georgia Institute of Technology Roon 223, $0^{\prime}$ Keefe Bldg.

Atianta, GA 30332

James L. Butler, Manager

SEA Southern Agri. Energy Center Coasta] Plain Experiment Statior

Tifton, GA 31793

David Carlson

Design Engineer

Superstill Technology, Inc.

897 Barron Avenue

Redwood City, CA 94063

Craig Chase

Bioenergy Project Management. and Consultation

12840 S.E. 40th, Lane A-4

Bellevue, WA 98006

Karen Chopp, Manager

Resource Recovery

Kimberly-Ciark Corporation

Neenah, WI 54956

David F. Ciliberti

Fellow Engineer

Westinghouse Electric Corp.

1310 Beulah Road

Pittsburgh, PA 15235 
No. of

Copies

L. Davis Clements

Dept. of Chenical Engineering

Texas Tech University

P.0. Box 4679

Lubbock, TX 79409

Steve Cliriehens

Deputy Executive Director

Alternative Energy Corporation

300 Park Drive, Sujte 117

P.0. Box 12699

Research Triangle Park, NC 27709

John A. Coffman

Wright-Malta Corporation

Malta Test Station

Plains Road

Ballston Spa, NY 12020

John Cox, Manager

Organic Chemistry

Gas Research Institute

8600 West Bryn Mawr Avenue

Chicago, IL 60631

Scott Crick

Energy Technology

14903 - 175th S.E.

Renton, WA 98056

Janet Cushman

Environmental Sciences Division

Oak Ridge National Laboratory

P.0. Box $X$

Cak Ridge, TN 37830

David H. Liwson

Forestry Research Consultant

The Conservation Foundation

$1835 \mathrm{~N}$. Stevens Street

P.0. Box $132 i$

Rhinelander, WI 54501

D. R. (Dave) Derry

Pyrenco Inc.

231 Phoerix Way

Voncouver, WA 98661
No. of

Copies

James P. Diebold

Solar Energy Research Institute

1617 Cole Boulevard

Golden, CO 80401

Lawrence Dobson

Northern Light R\&D

1385 - 33rd Avenue South

Seattle, WA 98144

Otto C. Doering, III

0irector, Energy Policy Research and Information Program

Purdue University

West Lafayette, IN 47907

Terry L. Donaldson

Oak Ridge National Laboratory

Building 4505, Mail Stop 27

P.0. Box X

Oak Ridge, TN 37831

Richard L. Durham

Chairman, Wood Energy Coordination Group

4863 Sage Hen Way

Lake Oswago, OR 97034

F. J. Dyches, Manager

Energy Utilization

Camas Mili

Crown Zellerbach

Camas, WA 98607

Lowe11 Endahl

National Rural Electric

Cooperative Association

1800 Massachusetts Avenue, N.W.

Washington, D.C. 20036

Paul Erickson

Rexnord

EnviroEnergy Techrology Center

5103 West Beloit Road

P.0. Box 2022

Milwákee, WI 53201 
No. of

Copies

Charles Eumurian

Vice President

Engineering and Manufacturing

Enerdyne Corporation

7430 Washington Ave. South

Minneapolis, MN 55344

Bob Evans

Solar Energy Research Institute

1617 Cole Blvd.

Golden, CO 80401

Herman F. Feldmann

Battelle-Columbus Laboratories

505 King Avenue

Columbus, $\mathrm{OH} 43201$

Sidney Firstman, President

Biomass Energy Research Association

Georgia Institute of Technology

O'Keefe Building

Atlanta, GA 30332

James Fisher

Fiber Fuels Institute

310 Cedar St. Suite 400

St. Paul, MN 55101

Virgil J. Flanigan

Gasification Research on Wood

Univ. of Missouri-Rolla

Rolla, MC 6540 ?

Roger Gaire

Business Development Marager

Foster Wheeler Synfuels Corp.

110 South Orange Ave.

Livingston, NJ 07039

Kenneth H. Gilbert, Chairman

Enerdyne Corporation

7340 Washington Avenue South

Minneapolis, Mill 55344

Mary Wolter Giass

Fred C. Hart Associates, Inc.

1110 Vermont Ave. NW, Suite 410

Washington, DC 20005
No. of

Copies

Jerome S. Goldhammer

Director of Engineering

AETA Corporation

Glynn House

Westford Road

Tyngsboro, MA 01879

C. W. Gorton

School of Chemical Engineering

Georgia Institute of Technology

Atlanta, GA 30332

W. Scott Cray

Executive Engineer

Research and Engineering

Bechtel Group, Inc.

Fifty Beale Street

P.0. Box 3965

San Francisco, CA 94119

Troy R. Green, Director

Alternative Energy Development

Standard $0 i l$ of Indiana

AMOCO Research Center

Warrenville Road

P.0. Box 400

Naperville, IL 60540

Howard Haines

Energy Division DNRC

32 South Ewing

Helena, MT 59601

Dave Halltuerg, President

Renewable Fueis Association

499 South Capital Street

Washington, D.C. 20003

Joseph T. Hamrick

Aerospace Research Corporation

5454 Jae Valley Road

Roanoke, VA 24014 
No. of

Copies

James $E$. Helt

Chemical Engineer

Argonne National Laboratory

Building 205

9700 S. Cass Avenue

Argonne, IL 60439

R. Anthony Henrick

Central Plants, Inc.

6140 Bristol Parkway

P.0. Box 3233

Culver City, CA 90230

William J. Herz

267 Woodiand Hills

Tuscaloosa, AL 35405

Richard $\mathrm{Hill}$

Dept. of Industrial Coop.

University of Maine

109 Boardman Hall

Orono, ME 04473

John C. Hiiliard

Conibustion and Fuel

Research Incorporated

857-9 South Wagner Road

Ann Arbor, MI 48103

Brad Holioman

New York State Energy Research

\& Development Authority

Agency Bldg. \#2

Empire State Plaza

Albany, NY 12223

Randy Hoskins

TransEnergy Systems

14711 North Easy 29th P1.

Bellevue, WA 98007

W. Densmore Hunter, Manager

Energy Technology Department

Weyerhaeuser Company

WTC-1B-30

Tacoma, WA 98477
No. of

Copies

\author{
Allen Jaisle \\ DOE Planning and Development \\ State of Minnesota \\ 2728 Chowen Avenue South \\ Minneapolis, MN 55416 \\ Branyon D. Jarrett, Jr., \\ Wood Energy Engineer \\ Georgia Forestry Comission \\ 7 Martin Luther King, Ur. Dr., SW \\ Atlanta, GA 30334
}

Paul C. Juhasz

Washington State Energy Office

lst Floor, ER-11

$400 \mathrm{E}$. Union

Olympia, WA 98504

John Kadyszewskj

USAID/TVA

AT/EY SA-18, Rri. 509

Washington, D.C. 20523

David Keenan

National Wood Energy Association

P.0. Box 4548

Portsmouth, NH 03801

James D. Kerstetter

kashington State Energy Office

State of Washington

400 E. Union, lst Floor, ER-11

OTympia, WA 98504

Donald L. Klass

Institute of Gas Technology

I IT Center

3424 South State Street

Chicago, IL 60616

William H. Klausmeier

Syivatex Corporation

241 Geneva Avenue

Elmhurst, IL 60126 
No. of

Copies

James A. Knight

Eng. Experimental Station Area 2

Georgia Institute of Technology

Atlanta, GA 30332

Steve Kohan

Electric Power Research Institute

3412 Hillview Avenue

P.0. Box 10312

Palo Alto, CA 94303

Arthur L. Koh1

Program lianager

Environmenta? \& Energy Systems Div. Rockwell International Corporation

8900 De Soto Avenue

Canoga Park, CA 91304

Allen M. Koleff

Director of Technology

Stone Container Corp.

P.0. Box 427

Franklin, OH 45005

Herbert M. Kosstrin

Stone \& Webster Engineering Corp.

¿45 Sumrier Street

Boston, MA 02107

A. W. Kramer

Thermal Energy Systems

The Proctor and Gamble Co.

6105 Center Hiil Road

Cincirinati, $\mathrm{OH} \quad 45224$

Barbara Krieger

Department of Chemical Engineering

University of Washington

Benson Hall BFlO

Seattle, WA 98195

James Kuester

Dept. of Chem. Engineering

Arizona State University

Tempe, AZ 85281
No. of

Copies

\author{
Harry La Fontaine \\ 1995 Keystone Blvd. \\ Miami, FL 3318 I \\ Michae? Lambert \\ USDA Forest Services \\ 809 NE 6 th Avenue \\ Portland, OR 97232 \\ Larry Larson \\ Southern California Edison \\ P.0. Box 800 \\ Fosemead, CA 91770 \\ R. Eric Leber \\ Director of Energy Research \\ American Pubic Power Assoc. \\ $2301 M$ Street, NW \\ Washington, D.C. 20037 \\ Leslie S. Levine \\ Vice President \\ Biomass Energy Research As50c. \\ Fusion Systems Corporation \\ 12140 Parklawn Lr. \\ Rockville, MD 20852 \\ Robert S. Loboda \\ Northwest Division \\ Rust Internationa? Corporation \\ P.0. Box 25374 \\ Portland, OR 97225 \\ Glenn H. Lovin \\ Executive Director \\ International Cogeneration Society \\ 1111 - 19th Street N.W. \\ Suite 1075 \\ Washington, D.C. 20036 \\ Michael Z. Lowenstein \\ Solar Fuels \& Chemical Research Div. \\ Solar Energy Research Institute \\ 1617 Cole Boulevard \\ Golden, C0 80401
}


No. of

Copies

Dean B. Mahin

International Energy Proj.

Box 591

Front Roya 1, VA 22630

Philip C. Malte

Department of Mechanical Engineering

University of Washington

Mechanica? Engineering, FU-10

Seattle, WA 98195

Eliseo C. Miariani, President

Marelco, Incorporated

3900 Mt. Vernon Ave.

P.0. Box 5048

Alexandria, VA 22305

Van Marquis

PCC Incorporated

Kansas Cjty, MO 64108

Thomas F. McGowan

Wood Energy Systemis Branch

Eng. Experimental Station

Georgia Institute of Tech.

Atlanta, GA 30332

Frank McMlanus

Resource Recovery Report

$1707 \mathrm{H}$ Street NW, Suite 607

kashington, D.C. 20006

Thomas R. Miles

Consuiting Design Engineers

5475 S.W. Arrowwood Lane

Portland, OR 97225

Bennett Miller

Fred C. Hart Associates, Inc.

1110 Vermont Ave. NW, Suite 410

washington, DC 20005

G. R. Miller

BTack and Veatch

1500 Meadow Lake Parkway

P.0. Box 8405

Kansas City, NO 64114
No. of

Copies

Thomas A. Mitre Solar Energy Research Inst. 1617 Cole B1vd. Golden, C0 80401

Boyd Montgomery

Nationa 1 Synfuels, Inc.

P.0. Box 209

Jacksonville, FL 32203

Fredrick E. Moreno

Advanced Energy Applications, Inc. 1386 Holt Avenue

Los Altos, CA 94022

Ethelyn P. Motley

Assistant Manager, Engineering

Chemical Engineering Laboratory

TRW Energy Development Group

Building 01, Room 2251

One Space Park

Redondo Beach, CA 90278

Ronald Mueller

Energy \& Environmental Systems

Division

Argonne National Laboratory

9700 South Cass five.

Argonne, IL 60439

Ping-Kuen (Eric) Mun

ARCO Solar Industries

BioEngineering Center

P.0. Box 2600

Dublin, CA 94566

Wayne K. Murphey

Cooperative State Research Service

Office of the Administrator

U.S. Department of Agriculture

Washington, D.C. 20250

Dennis Nelson

West Vaco Corporation

Covington, VA 24426 
No. of

Copies

Richard A. Nissen

Senior Mechanical Engineer

$0 i 1$ Dri Corp. of America

520 North Michigan Avenue

Chicago, IL 60611

E. F. (Woodie) 0liver

Field Adviser, Energy Integrated

Farin Program

Agricultura? Engineering Dept.

University of Illinois

at Urbana-Champaign

Urbana, IL 61801

Keliy 0lson

Biomenergy Program Special ist

Idaho Oepartment of Water Resources

Statekouse

Boise, ID 83720

Michael Unischak

Institute of Gas Technology

IIT Center

3424 South State Street

Chicago, IL 60616

Forrest E. Orr

Pyros, Inc.

656 Quince Orchard Road, Suite 304

Gaithersburg, MD 20760

Mark Paisiey

Eattelle-Columbus Laboratories

505 King Avenue

Columbus, $\mathrm{OH} 43201$

Archie H. Perugi

Manager, Engineering

Energy Appii. Frog. Dept.

General Electric Company

Schenectady, NY 12345

William A. Peters

Massachusetts Irst. of Tech.

E40-419 (Energy Laboratory)

Cambridge, MA 02139
No. of

Copies

Donald Petty

Technical Information Branch

Solar Energy Research Institute

1617 Cole Bivd.

Golden, CO 80401

Robert S. Pile

Biomass Fuels Program

Tennessee Valley Authority

Muscle Shoals, AL 35660

Donald W. Pingrey

Vice President

Trans Energy Systems

11441 Willows Road

Redmond, WA 98201

Kumar Ramohalli

Jet Propulsion Laboratory

Cal ifornia Institute of Tech.

4800 Oak Grove Drive

Pasadena, CA 91109

Jack Ranney

Environmental Sciences Oivision

Oak Ridge National Laboratory

P.0. Box $X$

Oak Ridge, TN 37830

Zenon Redkevitch

Eng. Experiment Station

Georgia Institute of Tech.

Atlanta, GA 30332

Tom Reed

Solar Energy Research Inst.

1617 Cole Blvd.

Golden, C0 80401

Joe Roethe1 $i$

Assist. Mgr., Biomass Fuels

Office of Agricultural and

Chemical Development

Tennessee Valley Authority

Muscle Shoais, AL 35660 
No. of

Copies

Peter Saggau

Energy \& Extractive

Union Bank

P.0. Box 3100

Los Angeles, CA 90051

George M. Savage

Vice President

Cal Recovery Systems Inc.

160 Broadway, Suite 200

Richniond, CA 94804

Milton D. Scheer

Chemical Kinetics Div. (542)

National Bureau of Standards

Washington, D.C. 20234

Regis Scheithauer

Jaycor Engineering

205 South Whiting St.

Alexandria, VA 22304

Helmut W. Schulz, President

Dynecology Incorporateo

611 Harrison Avenue

Harrison, NY 105'8

Charles D. Scott

Oak Ridge Nationar Laboratory

P.0. Box $X$

Oak Ridge, TN 37830

Lawrence N. Shaw

Department of Agricultural Eng.

University of Fiorida

Frazier Rogers Hall

Gainesville, FL 32611

Sinyan Shen

Energy \& Environmental Systems

Livision

Argonne National Laboratory

9700 South Cass Ave.

Argonne, IL 60439
No. of

Copies

David R. Shieids

Executive Vice President

National Synfuels, Inc.

P.0. Box 40239

239 Chambliss Street

Jacksonville, FL 32204

W. H. Smith, Director

Center for Biomass Energy Systems

University of Florida

3038 McCarty Hall

Gainesville, FL 32611

Jack Sowards

Box 178

Hayden Lake, ID 83835

Meyer Steinberg

Brookhaven National Laboratory

Upton, Long Island, NY 11973

Abu Talib

The Mitre Corporation/Metrek

Oivision

1820 Oolly Madison Blvd.

ilclean, VA 22102

C. Edward Taylor

Corporate Energy \& Env. Mgr. LouisianamPacific Corporation

P.0. Box 158

Samoa, CA 95564

Robert Van hiouk, Manager Woody Biomass Production Progran Environmental Sciences Divisiori

Oak Ridge National Laboratory

Bldg. 1505

P.0. Box X

Oak Ridge, TN 37836

Robert Hi. Vander Molen

Combustion Power Company

1346 Willow Road

Men lo Park, CA 94025 
No. of

Copies

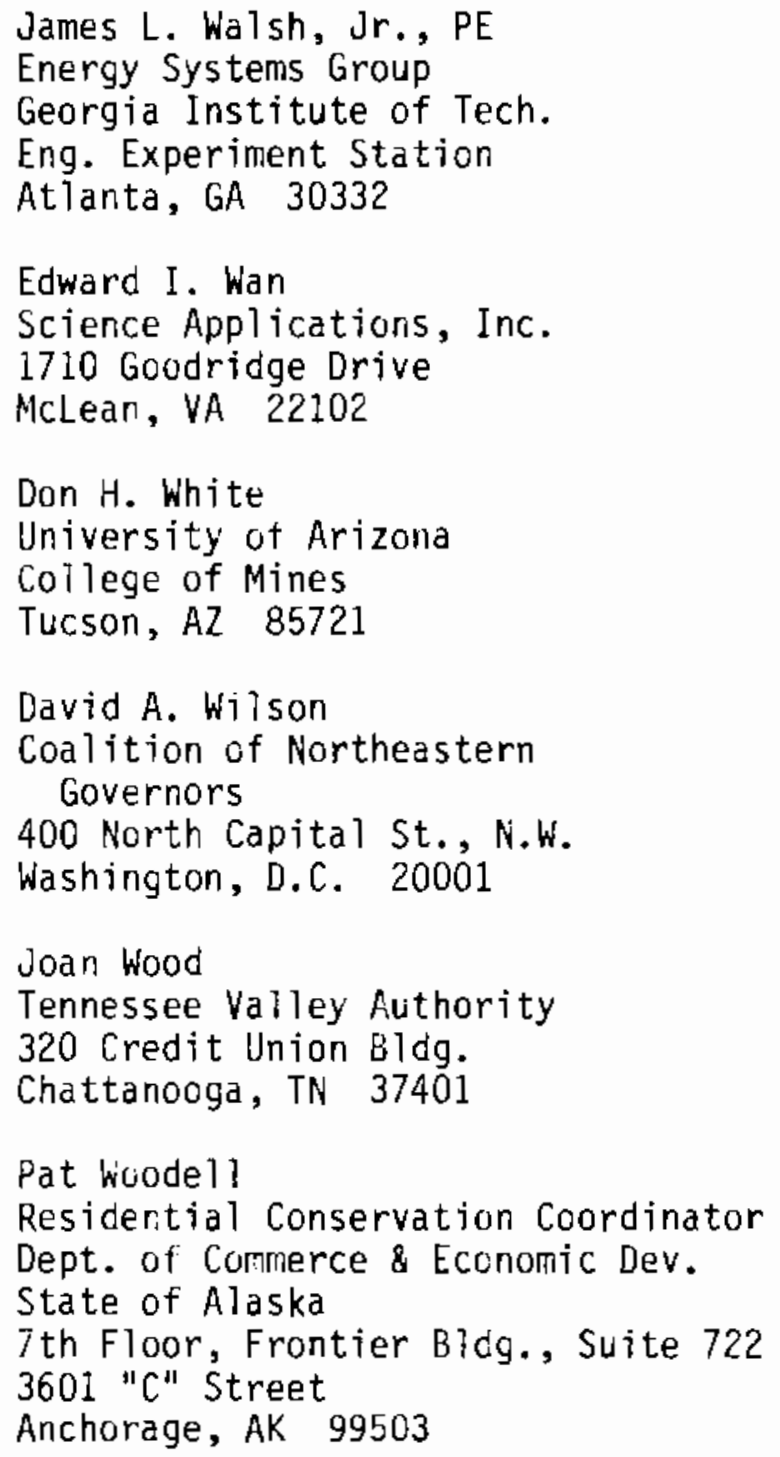

FOREIGN

Tony Bridgwater

The University of Aston in

Birmingham

Dept. of Chemical Engineering

Gosta Green

Birmingham, ENGLAND $847 \mathrm{ET}$
No. of

Copies

Dott. Guido Cogliati

AGIP Nucleare

ROME

3272661

M. GeTus

Creusot-Loire - Division Energie

BP 31 Cedex

$712 \mathrm{D} 8$ Le Creusot, FRANCE

,

Emilio M. A. Gomez

Agricultural Engineer

Empresa Nacional Adaro

De Investigaciones Mineras, S.A.

Serrans, 116

Madrid - 6, SPAIN

Jarmo Hailikas

Planning \& Marketing Office

Technical Research Centre of

Finlarid

Vuorimiehentie 5, SF-02150 Espoo 15

FINLAND

R. D. (Doug) Hayes

Energy, Mines and Resources Canada

580D Booth Street

ot tawa, CANADA KIA OE4

Carl Jensen-Holm

Danmarks Ingeniorakademi

Kemiafd. Bygn. 376

DK-2800

Lynby

DENMARK

Alain Joyeux

Sales Engineer

New Products Department

Creusot-Loire

P.0. Box 31

71308 Le Creusot

FRANCE 
No. of

Copies

J. A. Merladet
EYPROSA
Equipos y Processos, S.A.
Conde de Penalver, $45-3^{\circ}$
Madrid 6
SPAIN

G. Missoni

AGIP NUCLEARE

Roma - Via R. Cappelli 50

P.ome

ITALY

Raiph Overend

Energy Project

National Research Council of Canada

Ottawa, Ontario

KIA OR6 CANADA

I. Plumbley

Manager, Special Projects

INTEG-Intercontinenta? Eng. Ltd.

1155 West Pender St.

Vancouver, B.C.

CANADA V6E 2P4

Erik Rensfelt

Head, Gasification Technology

Department for Fuel Technology

Studsvik

Studsvik Energiteknik $A B$

S-611 82 Nykoping

SWEDEN

Hans-Rolf Schulten

Fachhochschule Fresenius

Department of Trace Analysis

Dambachtal 20

6200 WIESBADEN

Federà 1 Republic of Germany

D. 5. Scott

Departinent of Chenical Eng.

University of Waterloo

Waterloo, Ontario

CANAIIA N2L 2N7
No. of

Copies

Yrjo Solantausta, M.Sc.

Technical Research Centre of Finland

Fuel \& Lubricant Research Lab

Biologinkuja 5, SF-02150 Espoo 15

FINLAND

Barbara Summers

Director, Conservation and Renewable Energy office

Energy, Mines and Resources Canada 2078 - Second Avenue

Whitehorse, Yukon

$Y 1 A$ 1BI

\section{ONSITE}

2 DOE Richland Operations

Harold E. Ransom

Donaló R. Segna

37 Pacifjc Northwest Laboratory

E. G. Baker

S. N. Craig

J. C. Easterling

D. C. Elliott

M. A. Gerber

R. P. Marshal1

G. A. McAtee

L. K. Mudge

G. F. Schiefelbein (20)

D. J. Stevens

P. C. Walkup

Publishing Coordination (2)

Technical Information Library (5) 